\title{
Quantifying the impact of urban climate by extending the boundaries of urban energy system modeling
}

\author{
A.T.D. Perera ${ }^{1}$, Silvia Coccolo, Jean-Louis Scartezzini, Dasaraden Mauree \\ Solar Energy and Building Physics Laboratory (LESO-PB), Ecole Polytechnique Fédérale de Lausanne (EPFL), CH-1015 Lausanne, Switzerland
}

\begin{abstract}
Rapid growth of cities, concerns on global warming and depletion of fossil fuel resources call for sustainable energy solutions for cities. Distributed energy systems such as energy hubs offer promising solutions in this context. Evaluating the energy demand at urban scale is vital to support the design of energy hubs. However, most of the recent studies are based on bottom-up models and do not consider the energy demand in detail. More specifically, the influence of the urban climate on urban energy demand has not been considered so far in the energy system design process. In order to address this research gap, a novel computational platform is developed in the first part of this study, combining an urban climate model with a building simulation tool and an energy system optimization model. The second part of the manuscript is devoted to quantifying the impact of urban climate on energy system design and assessing the consequences of neglecting this specific aspect on energy system performance. Three case studies are conducted considering three building densities for the city of Nablus (building density at the periphery, center and future center of the city) in Palestine. Three scenarios representing 1) standalone buildings (present practice) 2) shadowing and longwave reflection (radiation heat transfer from the walls and the roofs of the buildings to the urban climate and to the sky) of neighboring buildings and 3) urban climate are considered for each case study when computing the energy demand. Subsequently, the energy system is optimized considering Net Present Value (NPV) and system autonomy level as the objective functions (Pareto optimization). The results of the study reveal that the urban climate has a notable impact on the energy demand and energy system design. More importantly, it is shown that the influence of urban climate results in higher fluctuations in the energy demand, which in turn results in a notable increase in the NPV (by up to 40\%). This further magnifies the increase in annual or peak demand. The study reveals that neglecting the influence of urban climate in the energy system design process can result in a performance gap in NPV, grid integration level, and greenhouse gas emissions and can impose reliability issues. The design tool introduced in this study can be used for urban planning to mitigate the aforementioned adverse effects.
\end{abstract}

\section{Keywords}

Urban energy systems, energy hub, urban climate, building simulation, energy system optimization, performance gap

\section{1) Introduction}

\footnotetext{
${ }^{1}$ Corresponding Author

Email:dasun.perera@epfl.ch,

Tel: +412169 35746, Fax: +41216932722

The short version of the paper was presented at ICAE2017, Aug 21-24, Cardiff, UK. This paper is a substantial extension of the short version of the conference paper
} 
Energy requirements in urban areas are rising at a rapid rate with the increase in urban population [1], [2]. In the context of actions against climate change, rapid depletion of fossil fuel resources and health concerns due to the emission of noxious gasses, a shift toward sustainable energy solutions in cities is therefore essential. The transition from fossil fuel based urban energy systems to $100 \%$ renewable energy systems [3], [4] is expected to be achieved within a few decades. To reach this goal, it is important to upscale planning from net-zero buildings to energy sustainable neighborhoods, districts and cities, since energy optimization of a district or a community is more cost effective than optimizing each building separately [5]. The objective is to lead urban planners to consider energy efficiency of the urban form and renewable energy integration simultaneously during the planning process [6]. Developing a holistic computational platform that bridges urban climate, building simulation and energy systems will be immensely helpful in this context.

Renewable energy integration and energy system design at urban and neighborhood scale have been widely discussed in recent studies at individual building, community, district and urban scale [7]-[11]. A comprehensive review on this is presented by Kastead et-al [12]. Perera et-al [13] have shown that integrated energy systems such as energy hubs can be used to integrate non-dispatchable renewable energy technologies beyond $60 \%$ of the annual demand. Morgan et-al [14] showed that more than $80 \%$ of the demand of a community can be supplied using onsite renewable energy technologies. Movraj et-al [15] have evaluated the influence of grid constraints when integrating renewable technologies into energy hubs. All these studies portray an optimistic picture of renewable energy integration at urban and neighborhood scale. However, simple integration of renewable energy technologies at any scale (building, community, urban or even direct grid integration) will result in poor utilization of the generated renewable energy [16]. Therefore, optimization tools are needed to reach the optimum energy mix.

Recently, a number of groups have developed optimization algorithms to implement efficient energy systems at urban and community scale while minimizing lifecycle cost, environmental impact, grid dependency etc. Samira etal [8], [17], [18] introduced a bi-level optimization algorithm to design distributed energy systems considering the dispatch strategy, which was later extended to include thermal networks. Optimum design of distributed energy hubs and the electrical and thermal distribution networks is addressed by Moraj et-al [19]. Simultaneous optimization of multiple energy hubs considering the interactions and the energy network is performed by Maroufmashat et-al [20]. A detailed cross comparison of different optimization algorithms used to design distributed energy systems can be found in Ref. [21]-[23]. These studies are solely focused on the generation and distribution aspects of the energy 
infrastructure where demand is considered as direct input to the optimization model. Therefore, the sensitivity of factors such as urban climate, building density and urban form on the demand is not properly considered. Improving energy efficiency and sustainability in the urban context depends on four leverages, i.e. urban morphology, building form and technology, occupant behavior and energy system [24]. The contribution of all these leverages is subject to the urban climate. On the other hand, the building stock itself has a notable impact on the urban micro climate. Quantifying the influence of urban climate on the building energy demand considering all the aforementioned factors is a challenging task. However, it is essential since the thermal behavior of the collective building stock is different from that of a stand-alone building; especially in an urban context [25]. According to Moonen et-al [26], a building in an urban area (compared to a stand-alone building) will more likely experience 1) higher air temperature due to urban heat islanding (UHI) effect, 2) lower wind speeds due to the wind shelter effect 3) reduced energy losses during the night due to the low sky view factor 4) changes in solar heat gain due to shadowing 5) changes in radiation balance due to the interactions in neighboring buildings. Neglecting the aforementioned factors may lead to significant miscalculation of the demand, beyond $30 \%$ according to Bozonnet etal [27], which will have a notable impact on energy system design. However, capturing the influence of solar radiation, long wave radiation and urban climate is a challenging task for hourly building simulation to be used for energy system sizing [25].

A number of groups have investigated effective methods to combine building simulation and energy system optimization. Evins [28] optimized the system configuration and building design by coupling energy system optimization with building simulation. A bi-level optimization algorithm is used in this context to optimize the energy system along with the building envelope, which takes considerably higher computational time (nine days without parallel processing). However, a standalone building is considered in this context without considering thermal interactions caused by the surrounding buildings. Wu et-al [29] optimized the building renovation level and energy system design simultaneously in order to identify the optimum energy system design and the buildings requiring renovation in the Swiss village Zernez. A representative set of buildings in which the energy interactions among the buildings are not considered, was selected in this study to represent the whole village,.

Fonseca et-al [30] introduced a city energy analysis tool to optimize urban energy systems using a bi-level optimization algorithm. A detailed hybrid model combining a physical model with a set of statistically representative archetypes is used in this study to obtain the energy demand in the context of energy system sizing [31]. The hybrid 
mode used in this work provides a better representation of the energy demand in an urban context. However, the energy interactions among the buildings are not considered in this study. Morgan et-al [14] developed a computational platform combining building simulation and an energy system optimization tool. The platform has the capability to assess the impact of shadowing and the long wave radiation at urban scale. However, the impact of the micro-climate is not considered in this work. A Swiss village with low building density is considered in this study; the sensitivity to shading and long wave radiation is therefore trivial. Furthermore, the impact of the building stock on energy system sizing is not considered. In conclusion, it can be stated that none of these studies comprehensively assess the impact of adjacent buildings on the thermal and electricity demand (due to lighting) in energy system sizing. Effects of shadowing and boundary layer are not considered in most of the instances. An adequate representation of buildings and their effects such as drag force, generation of turbulence etc. is crucial in the evaluation of local meteorological variables[32], [33] and therefore in the calculation of the building energy demand [34], [35] as it can impact the convective heat transfer coefficient [36]. Hence, it is important, with a view of energy system sizing, to represent the micro-climate accurately in the building simulation process.

Following these considerations, the present study focuses on extending the computational platform used to design urban energy systems by introducing an urban meteorological model. The computational platform consists of a building simulation model and an energy system sizing tool with an urban meteorological model as shown in Fig. 1. The introduction of the urban meteorological model facilitates presenting the influence of urban climate on building simulation and subsequently on the energy system design process. The influence of the urban climate on the energy demand is quantified considering different urban densities to introduce the present and future scenarios of Nablus, a city in Palestine. The demand profile notably influences the energy system design. Misrepresentation of the urban micro climate can lead to a performance gap in the energy system. This performance gap can be avoided through adequate representation (by using the computational platform introduced in this study) of the urban micro climate as shown in the final part of the manuscript. A concise overview of the computational platform combining different models is presented in Section 2. An extended explanation of the building simulation model and the urban climate model is presented in Section 3 followed by a description about the energy system optimization tool in Section 4. The influence of long wave radiation, urban climate and occupancy at urban context on the energy system sizing problem is taken into discussion in Section 5. 


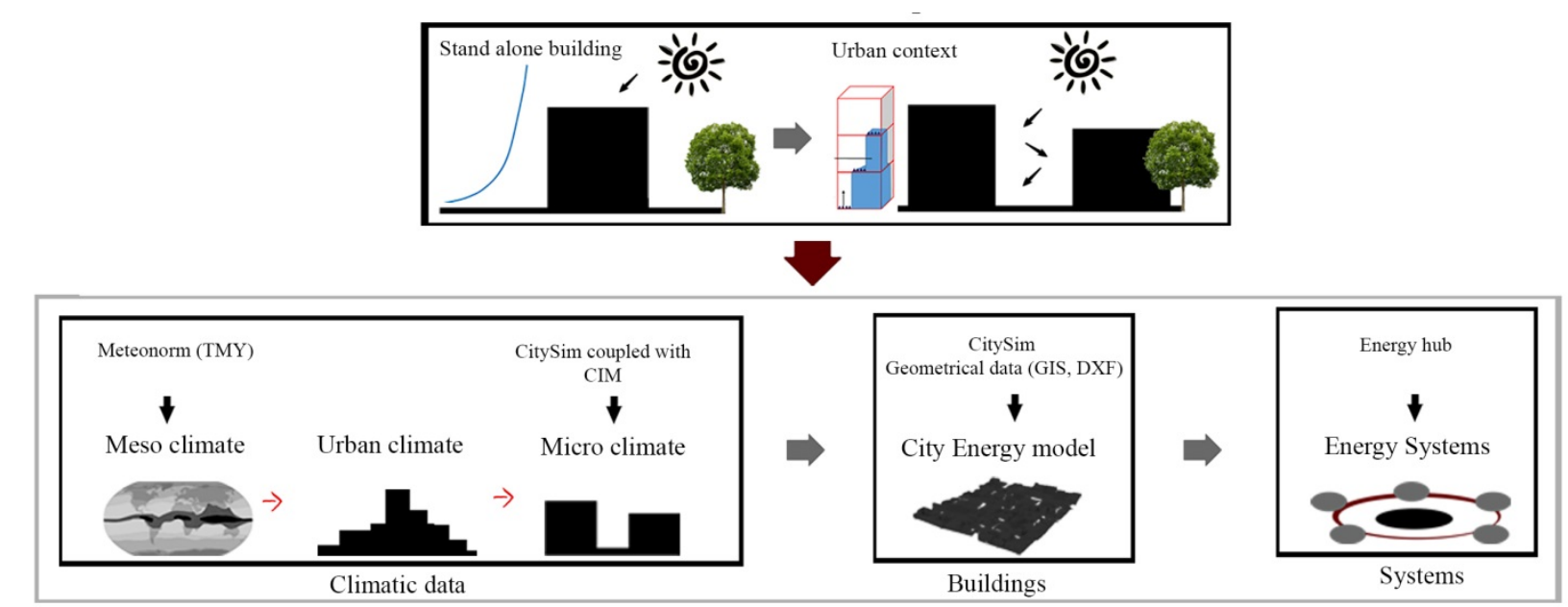

Fig. 1 Schematic overview of the computational platform.

\section{2) Overview of the computational platform and the case studies}

This section presents an overview of the computational platform developed in this study and the case study used to apply the novel computational platform. The platform combines urban microclimatic conditions, urban design, energy demand of building and optimization of energy system modelling. It is an attempt in the direction of creating a comprehensive design tool that offers a compromise between energy planning needs and the complexity of the urban metabolism. The platform is used to assess a real case study in order to quantify the influence of urban climate on the energy system. A brief over-view of the city considered for the case study and the methodology used to develop building archetypes that represent the compactness of the city at different levels is presented in Section 2.2.

\section{1) The computational platform}

Urban energy planning is a lengthy process that involves a considerable number of steps [37]. Energy system optimization plays an important role in this context as does evaluating the energy demand of the building stock. The coupling of buildings and urban climate is the main challenge to be faced when determining the energy demand of buildings using a bottom-up method. Taking into account the influence of urban climate on buildings and vice-versa may result in a significant change in the projected heating and cooling demand of the building stock and may lead to notable changes in energy system design. Hence, it is important to consider the impact of urban climate at the early design stage of the energy system. The main objective of the proposed computational platform is to combine an urban climate model with a building simulation model and an energy system optimization model in order to design urban energy systems. 


\subsection{1) Challenges in modeling the urban climate and promising paths}

The interaction between building stock and urban climate should be carefully decoupled when combining the urban climate model with building simulation. Developing an urban climate model alone is a challenging task due to the geometric complexity and the wide range of spatial and temporal scales required to characterize atmospheric phenomena [25]. A computational fluid dynamic (CFD) model is usually required to achieve a very high level of accuracy. A CFD model requires excessive computational resources and time when computing a time series data for wind distribution and temperature in an urban canyon layer. Therefore, simpler models which reduce the computational time and intensity are necessary. According to [25], urban canopy models can be effectively used to address the challenge with an acceptable level of accuracy. The multi-layer Canopy Interface Model (CIM) [32], [38] is hence used in order to provide the microclimate data for building simulation.

\subsection{2) Work-flow of the computational platform}

The urban energy planning process begins with the acquisition of required spatial and temporal data as inputs to the computational model. GIS based tools (e.g. QGIS) are used to collect the building information for the simulation. The 3D geometries of the buildings in the urban area are modelled using Rhinoceros, based on the information from QGIS. This is done to prepare the DXF data files as input for CitySim Pro[39] and CIM.

CitySim is an extension to SUNTool [40], which can consider the shading effect of adjacent buildings and longwave radiation due to the interaction among buildings. CitySimPro [39], [41] a software developed at the EPFL Solar Energy and Building Physics Laboratory (LESO-PB) is used in this study to simulate the building stock. CitySimPro uses a bottom-up approach when evaluating the hourly energy demand taking into account the fine details of the building stock. The radiation model inside CitySim, the Simplified Radiosity Algorithm (SRA) [42] can consider the shading effect of adjacent buildings and longwave radiation due to the interaction of buildings. Building simulation generally considers properties of the thermal shell, visible surface properties, occupancy profile, openings of the building through doors and windows etc. However, it is time consuming to collect all details precisely for each building forsimulations at building scale. Therefore, basic envelope details are obtained considering the construction year of the building. In addition, each building is represented by a single zone instead of multiple zones when evaluating the energy flow. Citysim computes the surface temperature of each building, which is subsequently imported to CIM. Based on the resulting wind speed, the air temperature is recalculated and fed back to Citysim to re-calculate the energy demand. 


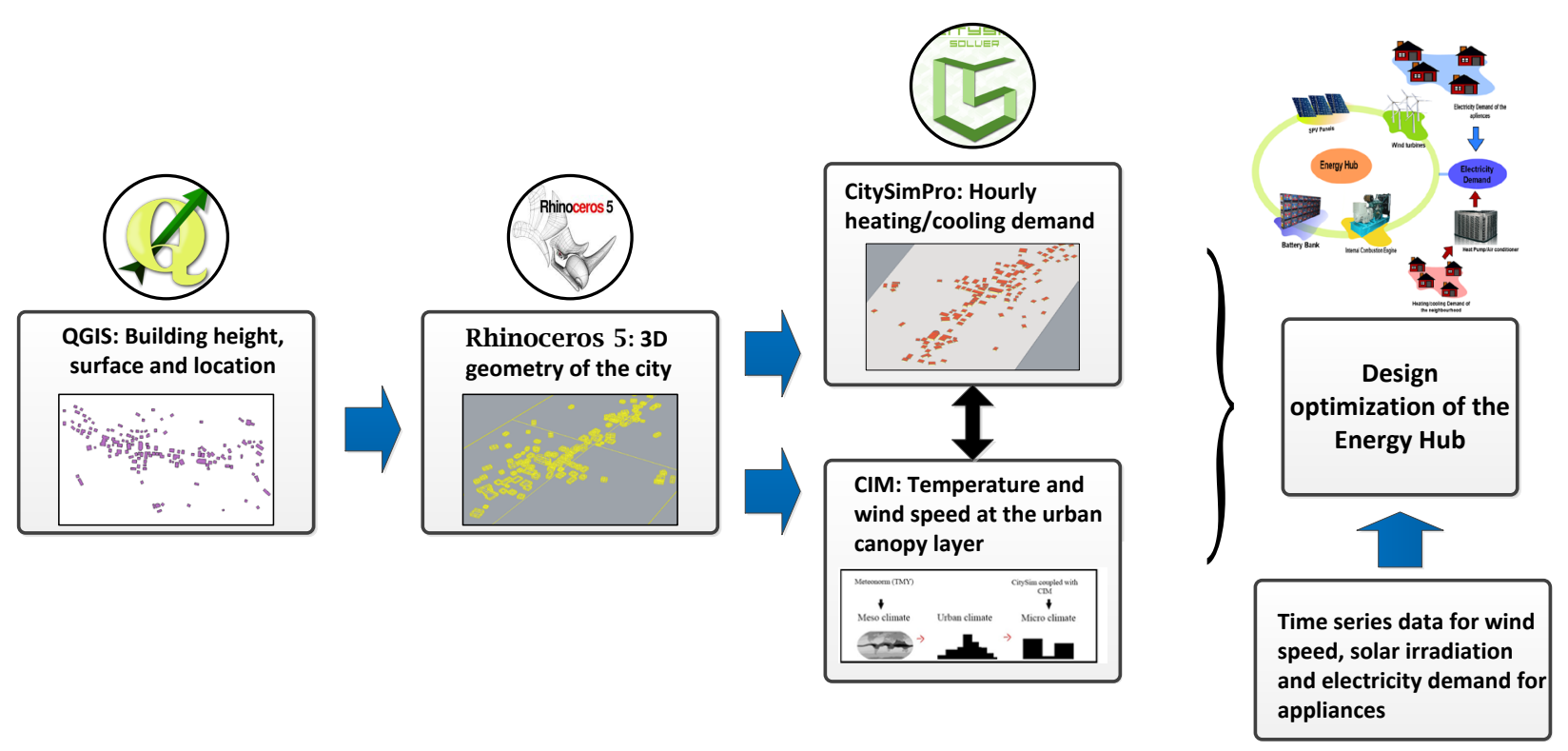

Fig. 2 Work flow of the computational platform

The hourly energy demand obtained from CitySim is subsequently used to optimize the energy system. A multi energy hub consisting of non-dispatchable renewable energy sources, storage and dispatchable energy sources is considered in this study. The energy hub optimization model presented in Ref. [13], [43] is used to optimize the system design of the energy system. An hourly time series of renewable energy potential and prices of system components are taken as the input to the computational model. A detailed description of the computational model used to design the energy system is presented in Section 4.

\section{2) Outline of the Case Studies}

The computational platform developed in this study is used to quantify the influence of urban climate on energy system design. A detailed description of the selected case study and the considered building stock is presented in this section.

\subsection{1) City of Nablus}


The city of Nablus $\left(32^{\circ} 13^{\prime} \mathrm{N}, 35^{\circ} 16^{\prime} \mathrm{E}\right)$, located in the northern part of the West Bank, is considered for the case study. The city presents a Csa climate (C: temperate; s: dry summer; a: hot summer), characterized by warm temperatures, low precipitations and high temperatures during the summer time. Nablus is located at $550 \mathrm{~m}$ above sea level and presents a particular topography, as it is positioned in a narrow valley, between Mount Ebal (940 meters) in the North, and Mount Gerizim (870 meters) in the South. In order to perform this study, the Al-Habaleh district (circa 130 buildings) is analyzed, within the old city; the district is characterized by dense constructions and narrow streets. The average annual temperature corresponds to $17.9^{\circ} \mathrm{C}$, with maximum temperatures during the summer time equaling to $36.8^{\circ} \mathrm{C}$, and the lowest temperature (during the month of December) equaling $1{ }^{\circ} \mathrm{C}$ (extracted from Meteonorm database [44]). The total annual precipitation corresponds to $315 \mathrm{~mm}$, and precipitation is completely absent during the summer season (from June to September). The wind blows mostly during the summer time, with an average speed of $3.5 \mathrm{~m} \mathrm{~s}^{-1}$ during the month of July.

\subsection{2) Use of archetypes}

Urban morphology is usually complex. Furthermore, buildings within a city are distributed with different densities and usually have diverse thermal characteristics. This makes it difficult to quantify the influence of urban climate on energy system design. In order to simplify, we worked with archetypes representing the urban fabric. Urban archetypes are amply used to simplify the complexity of the urban morphology in an effective way [24], [45]. The urban archetype influences the thermal performance, solar access and the ventilation as shown by Sanaieian et-al [46]. In this study, we limit the scope to a single urban archetype focusing more on the urban density. The height and the distance between buildings in urban archetypes present an average value of the building stock considered. By analyzing the old city center of the city of Nablus as well as the peripheral areas, the density of the two city areas was defined. The city center has a volume to site area ratio equal to 2.6. The periphery has a volume to site area ratio equal to 1.5. In order to represent these two configurations, we used archetype modelling, using both density characteristics, as presented in Figure 3. 


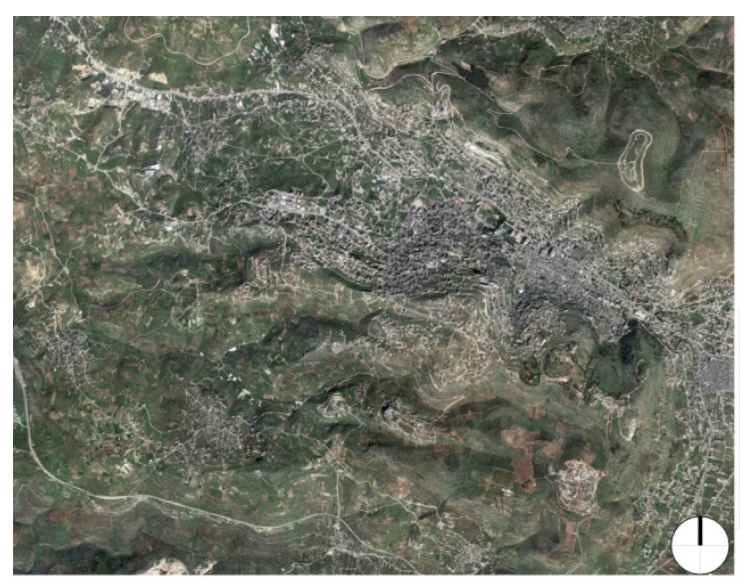

View from Google Maps

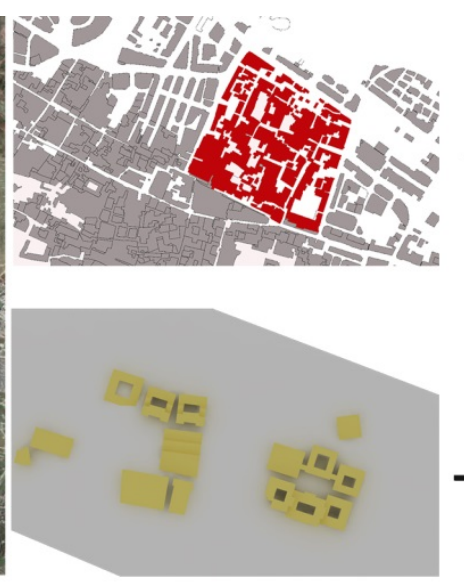

Plan view

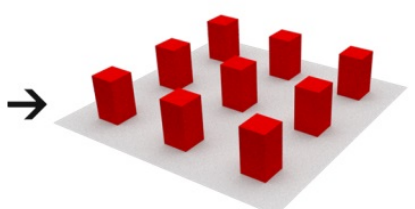

City center

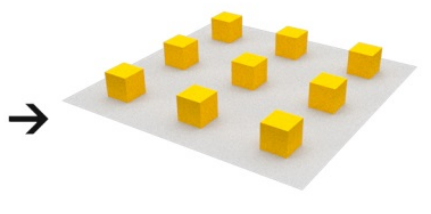

Periphery

Fig. 3 Archetype modelling as a function of the density of the site

\section{3) Computational model for urban micro climate and building simulation}

The coupling of a building simulation model (such as CitySim) with meteorological models is essential to represent the impact of buildings on climatic variables and to provide enhanced building energy simulation. Phenomena such as the Urban Heat Island [47] are not represented in TMY or a Meteonorm dataset, since they are usually collected outside of the city. This data then needs to be transformed to take into account the particularities of the urban climate and to provide useful data to building energy models. This is why it is proposed here to use the CIM-CitySim coupled model and to extend it further.

CIM is a $1 \mathrm{D}$ meteorological model [48] that can work offline as a stand-alone module while using as input data a climatic dataset (such as Meteonorm [44]). Alternatively, it can be coupled with a 3D meteorological model (such as WRF [49]). For the purpose of this study, since we are addressing the issue of energy systems, a typical meteorological year supplied by Meteonorm is used as boundary condition for CIM. The values are averaged over a period of 20 years for the irradiation and over 10 years for the wind speed and air temperature. CIM computes high resolution vertical profiles of the variables (such as the wind speed, direction and air temperature) considering the urban environment (for example considering the presence of buildings and their density). CIM resolves a diffusion equation derived from the Navier-Stokes equations but reduced to one direction only.

The differential equations for the momentum and the potential temperature can be written as Eq. 1 and 1' 


$$
\begin{gathered}
\frac{\partial u}{\partial t}=\frac{\partial}{\partial z}\left(\mu_{t} \frac{\partial u}{\partial z}\right)+f_{m}^{s} \\
\frac{\partial \theta}{\partial t}=\frac{\partial}{\partial z}\left(\kappa_{t} \frac{\partial \theta}{\partial z}\right)+f_{\theta}^{s}
\end{gathered}
$$

where $u$ is the mean horizontal wind component in the $x$ - or $y$-direction, $f_{m}^{s}$ and $f_{\theta}^{s}$ are the terms representing the momentum and heat fluxes exchanged between the flow and "solid" surfaces (ground or buildings here). The diffusion coefficients are computed according to a 1.5-order turbulent closure (Eq. 7 and 8 ) as proposed by Monin and Yaglom [50] according to Eq. 2:

$\mu_{t}=C_{e} \sqrt{e} l$ and $\kappa_{t}=\operatorname{Pr} \mu_{t}$

where $C_{e}$ is a constant, $e$ is the turbulent kinetic energy (TKE), Pr is the Prandtl number that represents the ratio between the momentum and heat diffusion coefficients, and hence depends on the stability of the atmosphere [51]. Subsequently, differential equations for momentum, potential temperature and TKE are solved using the finite volume method. Equations are taken from [48] take into account the obstacles density and height in the canopy.

The model has been coupled with the CitySim building simulation software (see Fig. 4) in order to determine the energy demand of a district [34]. The CIM-CitySim coupling has been tested in multiple cities [35], [52]-[54] and the method presented in this study could thus also be applied to other regions. Furthermore, the use of such a methodology has also been previously used to evaluate the building energy consumption at the city scale [55], [56]. Although the building geometries are simplified in CIM, the simulation of the wind speed is coherent with past findings [32], [57], [58]. The coupling of CitySim and CIM provides enhanced boundary conditions for both models. As described in Fig. 4 the simulation takes place in three steps. First a simulation with CitySim is performed with the Meteonorm data to obtain the surface temperatures. Secondly, CIM is forced with the surface temperature from CitySim to simulate the flow in the column module and to recalculate a high resolution vertical profile of meteorological variables, such as the air temperature and the wind speed. Finally, CitySim is provided with localized meteorological data to simulate the energy demand. The modification of the variables influences two main processes that are computed by CitySim: 


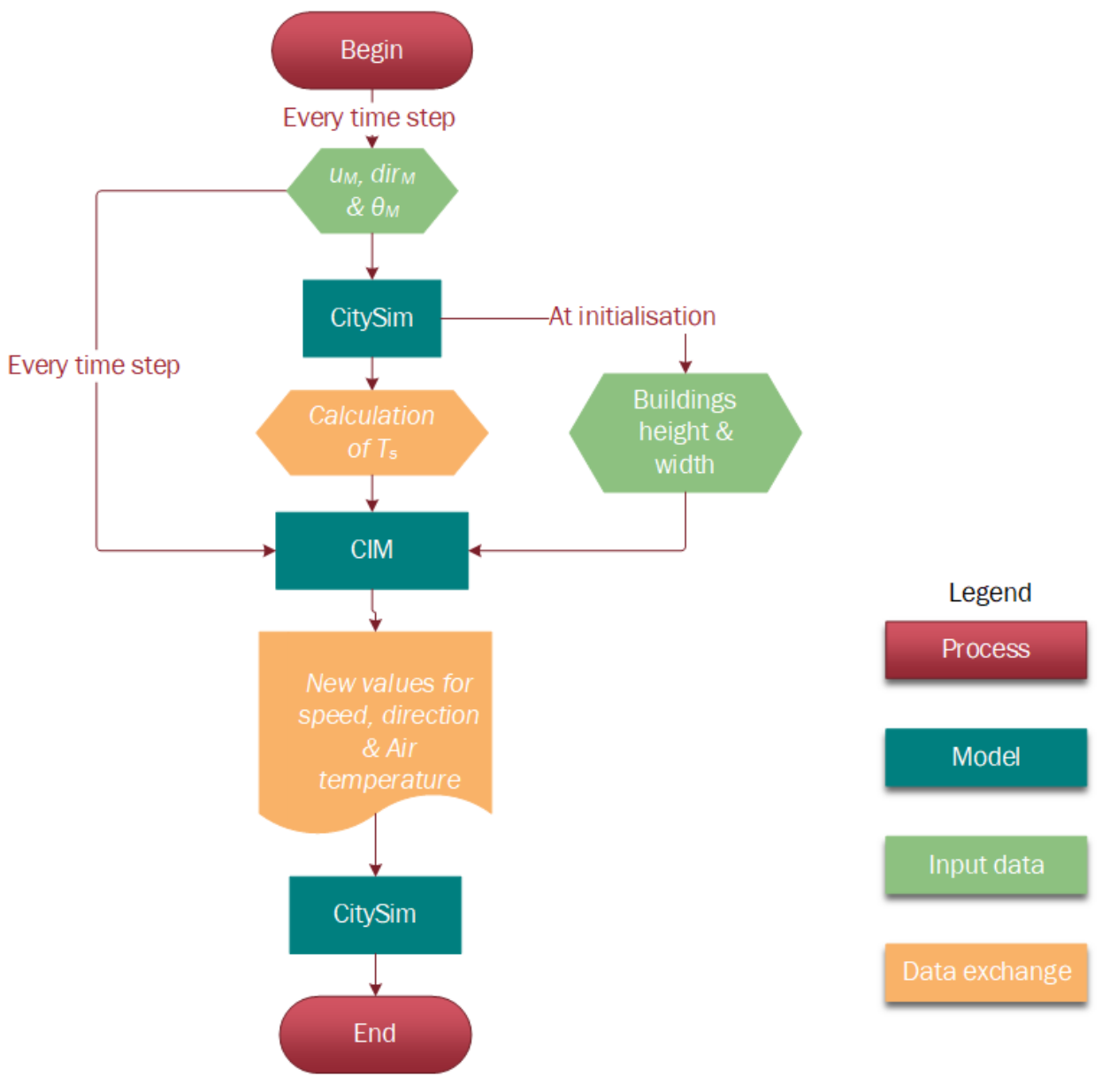

Fig. 4: CIM-CitySim flowchart adapted from Ref. [34]

First, the convective heat transfer coefficient for each surface $i$ at time step $t\left(h_{t}^{c, i}\left(W m^{-2} K^{-1}\right)\right)$ is given by Eq. 3:

$h_{t}^{c, i}=2.8+3 U_{t}, \quad \forall t \in T, \forall i \in I$

where $U_{t}$ is the wind speed. $h_{t}^{c, i}$ is then used in the calculation of the flux $Q_{t}^{c h, i}$ (Eq. 4):

$Q_{t}^{c h, i}=h_{t}^{c, i}\left(\theta_{t}^{s, i}-\theta_{t}^{a i r}\right) \forall t \in T, \forall i \in I$

where $\theta_{t}^{s, i}$ is the surface temperature in $\mathrm{K}$ and $\theta_{t}^{a i r}$ is the air temperature in $\mathrm{K}$. The longwave heat transfer is calculated as a function of the difference between the environmental temperature ( $\left.\theta_{t}^{\text {air }}\right)$ and the surfacetemperature.

Secondly, the longwave flux $Q_{t}^{l w, i}$ is computed in a similar manner considering the radiation heat transfer. The 
entire coupling process between CIM and CitySim is presented in Fig. 4. A full description of the CIM model as well as the equations used to take into account the obstacles density and height in the canopy can be found in Mauree et al. [32].

\section{4) Energy System design tool}

The main objective of the energy hub model is to optimize the energy system design. A multi energy hub (MEH) catering the energy demand for cooling, heating and power (CCHP) is considered in this study. The energy hub model introduced by Geidl et-al [59], which has been amply used to design and assess poly-generation systems [60], is used.. This model integrates energy technologies with different characteristics. Solar PV panels (SPV) and wind turbines are used as the non-dispatchable energy technologies in the energy hub (Fig. 5). An internal combustion generator or a gas turbine is used as the dispatchable source. A battery bank is used as the energy storage device. A ground source heat pump and a vapor compression air conditioner are used to cater the heating and cooling demands respectively. The MEH is expected to operate in connection to the Medium Voltage Grid (MVG). A time series of grid electricity prices is considered to represent the real time price in the MVG. Grid curtailments are introduced when selling and purchasing electricity to and from the MVG. Both system design and the operation strategy of the energy hub are optimized using the optimization algorithm. A concise description of the energy flow and cash flow models is presented in this section along with the formulation of objective functions. A bi-level dispatch strategy used for the energy flow management and the optimization algorithm used for the Pareto optimization are presented in the last part of this section.

\section{1) Energy and cash flow model}

The inputs to the computational model that computes the power generation using SPV panels and wind turbines are the hourly global solar irradiation on the tilted solar PV panel surface and wind speed at the wind turbine hub level. It is challenging to consider the impact of the urban context when sizing the energy systems. This requires prior selection of appropriate roofs and facades to install SPV panels, which constitutes another optimization problem within the energy system optimization problem already addressed. In order to simplify the procedure, a shading factor is introduced in this work. Wind turbines are expected to be installed in close proximity to the city in which the wind speed is adjusted to match the urban context according to Ref. [61]. 


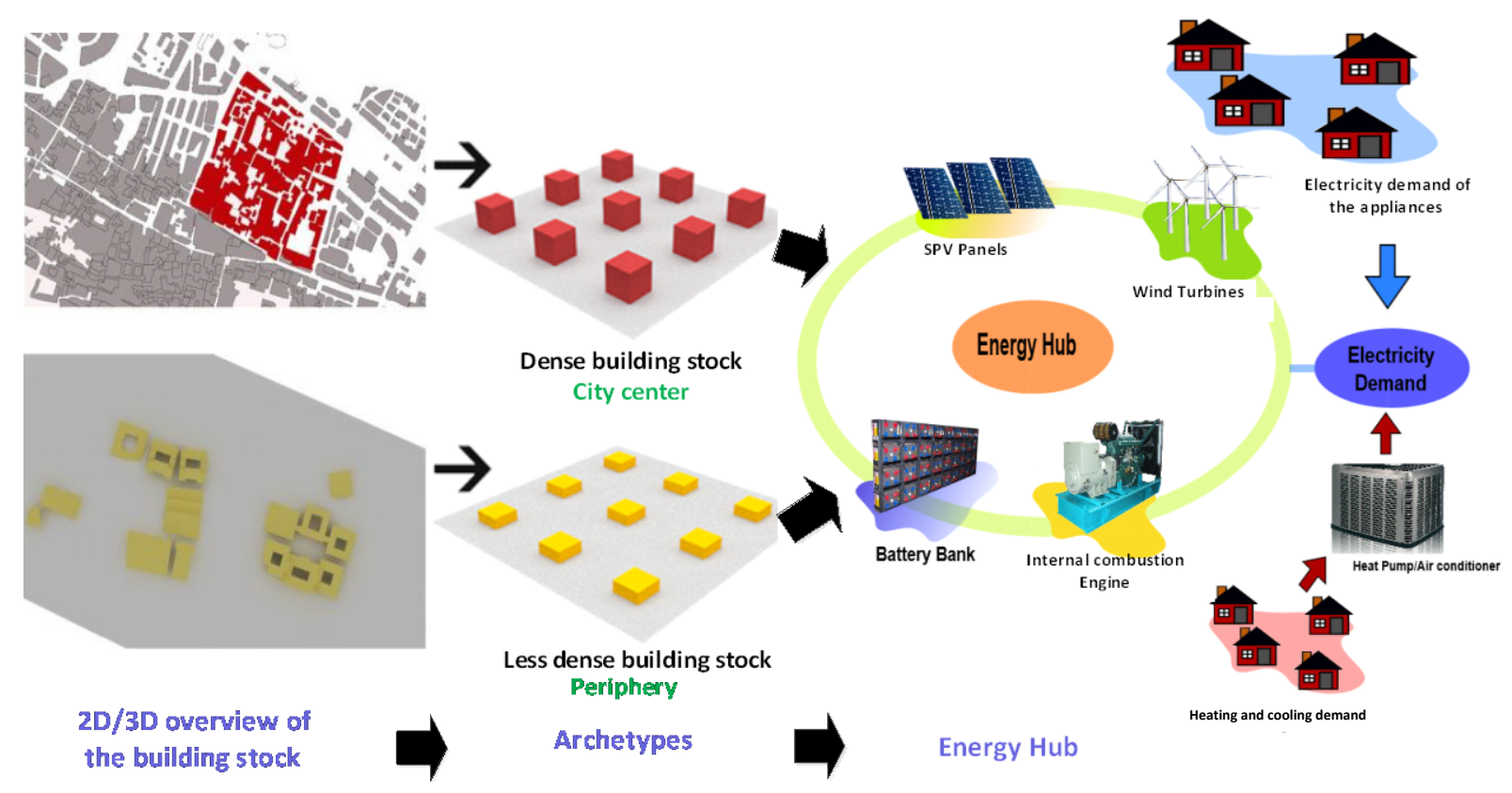

Fig. 5: Overview of the energy system

The Durisch model [62], which considers the global solar irradiation on the tilted SPV panel, cell temperature, and air-mass is used to compute the efficiency of the SPV panels. Subsequently, power generated from the SPV panels is calculated using Eq. 5. Cell temperature is computed considering the ambient temperature and the global solar irradiation on the tiled SPV panel according to Ref. [62].

$E_{t}^{S P V}=G_{t}^{\beta} \eta_{t, x^{S P V}}^{S P V} A_{x^{S P V}}^{S P V} N^{S P V} \varsigma, \quad \forall t \in T$

In this equation, $G_{t}^{\beta}, \eta_{t, x^{S P V}}^{S P V}, A_{x^{S P V}}^{S P V}, N^{S P V}, x^{S p v}$ and $\mathcal{\zeta}$ denote the global solar irradiation on the tilted PV panel, the efficiency of the SPV panel, the number of PV panels obtained using the optimization algorithm, the type of SPV panel (mono-crystalline, poly-crystalline etc.) and the shading factor respectively.

Power generation using the wind turbines is computed according to Eq. 6 following the method used for SPV panels.

$E_{t}^{\text {Wind }}=E_{t, x^{\text {wind }}}^{\tilde{W}}\left(\mathrm{v}_{\mathrm{t}}\right) \mathrm{N}^{\mathrm{w}} \eta^{\text {w-losses }}, \forall t \in T$ 
In Eq. 8, $\tilde{E_{t}^{W}}\left(\mathrm{v}_{\mathrm{t}}\right)$ denotes the wind power generation from a single wind turbine, which depends on the wind speed at the hub level and the characteristics of the power curve. $\mathrm{N}^{\mathrm{w}}$ and $\eta^{\text {w-asese }}$ denote the number of wind turbines in the system (which is obtained using the optimization algorithm) and the power losses. Renewable power generation of the system $\left(E_{t}{ }^{R E}\right)$ is computed adding the power generation of SPV panels and wind turbines. Similarly, power generation from the dispatchable source and the energy conversion through the battery bank are computed. An extended explanation of the energy system model can be found in Ref. [16], [63], [64]. Power generation from dispatchable sources and charging and discharging processes of the battery bank are determined using the dispatch algorithm explained in Section 4.2.

\subsection{1) Grid Integration Level}

The energy system interacts with the MVG when catering to multi-energy demand. The dispatch strategy evaluates the level of grid interaction based on demand, renewable energy generation, state of charge of the battery bank and price of grid electricity. Maintaining minimum interactions with the grid is always encouraged from the perspective of grid stability (which will result in a higher autonomy level). However, maintaining a higher autonomy level result in poor utilization of renewable power and higher investment into energy storage and dispatchable sources. Hence it is important to achieve a proper balance between cost and autonomy level, which can be assessed using the Pareto front considering NPV and Grid Integration (GI) level. GI is defined in this study according to Eq. 7 following the previous work of the authors in Ref. [13].

$G I=\sum_{\forall t \in T} E_{t}^{I G} / \sum_{\forall t \in T} E_{t}^{D}$

In this equation, $E_{t}^{I G}$ and $E_{t}^{D}$ denote respectively the energy imported from the grid and the demand of the energy hub.

\subsection{2) Net Present Value (NPV)}

The net present value of the system is computed considering the initial capital cost and operation and maintenance cost (O\&M) of the system. Initial capital costs of the system include the acquisition expenditure for purchasing wind turbines, SPV panels, dispatchable energy source (internal combustion generator (ICG)), battery bank and the 
installation cost. O\&M consists of two components; i.e. fixed operation and maintenance cost (FOM) and variable operational and maintenance cost (VOM). FOM includes the annual maintenance cost for the system components, fuel cost and net expenditure for grid interactions. VOM includes the replacement cost for the dispatchable energy source and battery bank depending upon the usage.

\section{2) Dispatch strategy}

A dispatch strategy is used to manage the energy interactions with the grid, energy storage and dispatchable source. A bi-level dispatch strategy based on fuzzy logic and finite automata theory is used in this study. A fuzzy logic controller is used to determine the operating load factor of the dispatchable energy source. The difference between hourly demand and renewable power generation, state of charge of the battery bank and the price of electricity in the grid are considered as inputs to the fuzzy logic controller when determining the operating load factor of the dispatchable source. After determining this parameter, the net power generation within the system is computed. Energy interactions with the grid and the battery bank are determined subsequently based on a finite state space. State transition rules and fuzzy rules are optimized using the optimization algorithm. An extended explanation of the dispatch strategy can be found in Ref. [13].

\section{3) Optimization algorithm}

The design and the operation strategy of the energy system are closely coupled and therefore need to be optimized simultaneously. This study limits its scope to the design and operation of the energy system. Design optimization of the distribution network is not considered, but will be focused on in future studies. The decision space of the optimization problem includes variables related to both system design and operation strategy. Decision space variables are mapped into the objective space through an hourly time series simulation. The objective functions, constraints and different cases considered in this work are presented in Table 1. Subsequently, a heuristic algorithm is used to conduct a Pareto optimization. Heuristic algorithms have been amply used to optimize the system design of distributed energy systems. The steady state epsilon dominance method is used conduct Pareto optimization. A polynomial-mutation operator and simulated binary crossover operator [87] are used along with differential evolutionary operators [77]-[79] in the reproduction of the population. The constraint tournament method [65] is used to handle constraints in the optimization algorithm. An extended explanation of the optimization algorithm is presented in Ref. [13], [66] 
Table 1 Objective functions and the constraints considered for Pareto optimization.

\begin{tabular}{cccc}
\hline Location & $\begin{array}{c}\text { Objective Function 1- } \\
\text { Objective Function 2 } \\
\left(\mathbf{F}_{\mathbf{1}}-\mathbf{F}_{\mathbf{2}}\right)\end{array}$ & Constraints \\
\hline $\begin{array}{c}\text { Nablus city } \\
\text { center }\end{array}$ & NPV-Grid Interactions & Standalone, Meteonorm, CIM & \\
$\begin{array}{c}\text { Nablus Periphery } \\
\text { Nablus future } \\
\text { city center }\end{array}$ & NPV -Grid Interactions & Standalone, Meteonorm, CIM & $\begin{array}{c}\text { Power supply } \\
\text { reliability }\end{array}$ \\
\hline
\end{tabular}

\section{5) Results and discussion}

The influence of the urban climate is an important factor to be considered when designing urban energy systems. However, the impact of urban climate on the energy system is not direct. It expresses itself in the heating and cooling demand of the building stock, which makes it more complex. A comprehensive assessment of the impact of urban climate on the energy demand and its importance on the energy system design is discussed in this section.

\section{1) Influence of urban climate on the energy demand}

The heating and cooling demand, as quantified by means of archetype modelling, presents an interesting information on the influence of urban climate on the energy demand. In order to reach a better understanding of the impact of meteorological data and urban compactness, a comprehensive assessment is performed for the archetype building stock in the city of Nablus, focusing on the variation of the heating and cooling demand. In order to support the analysis, three scenarios are considered i.e. standalone, Meteonorm and CIM. The standalone scenario neglects the thermal interactions with the neighboring buildings when computing the energy demand for the archetype. This is the method often practiced when computing energy demand for a stock of buildings. Meteonorm considers the shading effect and long wave radiation due to the adjacent buildings. Finally, CIM considers the microclimate in addition to the Meteonorm model. The influence of building density on energy demand in different urban densities is subsequently analyzed for each scenario. This is then used to understand the changes required in energy system design in Section 5.3. 


\subsection{1) Influence of the urban density on energy demand}

Urban compactness notably influences building energy demand, which needs to be taken into account in energy system sizing. Three cases (represented by three different archetypes of building stock) are considered in this work in order to assess its impact. Case 1 corresponds to the building density it the center of the city of Nablus. Case 2 considers the building density at the periphery, which is less compact compared to the center. Case 3 considers a future expansion scenario for Case 1, in which the building density of Case 1 is expected to grow further. Case 3 has the highest building density, followed by Cases 1 and 2. The peak and annual demand for each case are presented in Table 2. Furthermore, the percentage increase in annual demand and peak demand is presented in Table 2.

Peak and annual demand for the standalone scenario of Cases 1 and 3 are the same; they are different from Case 2. The height of the building archetypes is considered to be same even after expansion, which makes the set of buildings look the same in the standalone scenario. The heights of the buildings are reduced when moving into the periphery, which results in a reduction of the energy demand (when considering the standalone scenario for Case 2). The percentage increase in annual and peak demand is trivial for Cases 1 and 2 when moving from the standalone to the Meteonorm scenario. This shows that the influence of shadowing and longwave radiation is negligible when considering Cases 1 and 2. However, a noticeable increase in both peak and annual demand is observed when moving from the standalone scenario to the Meteonorm scenario in Case 3. This reveals that the influence of shadowing and longwave radiation is observed at very high urban densities. A noticeable increase in annual and peak demand is observed when moving from the standalone to the CIM scenario. This suggests that the wind speed and air temperature at the urban canyon layer have a noticeable impact. When moving to Case 3 , this increases the annual and peak demand by $13 \%$ and $10 \%$ respectively. These results make it interesting to further analyze the influence of the wind speed and ambient temperature on energy demand. To achieve this, wind speed and ambient temperature values at higher temporal resolution are taken. 
Table 2 Influence of the urban compactness on the energy demand

\begin{tabular}{|c|c|c|c|c|}
\hline Case & & Standalone & Meteonorm & $\mathrm{CIM}$ \\
\hline \multirow{5}{*}{3} & Annual Demand (GWh/year) & 1.16 & 1.21 & 1.41 \\
\hline & Peak heating/cooling demand ( $\mathrm{kWh}$ ) & 536.6 & 557.1 & 619.3 \\
\hline & Standalone $(\%)$ & & 4.13 & 17.73 \\
\hline & Increase in Peak Demand compared to & & & \\
\hline & Standalone $(\%)$ & & 3.69 & 13.36 \\
\hline \multirow{6}{*}{2} & Annual Demand (GWh/year) & 0.73 & 0.73 & 0.82 \\
\hline & Peak heating/cooling demand (kWh) & 334.4 & 334.8 & 363.8 \\
\hline & Increase in annual demand compared to & & & \\
\hline & Standalone (\%) & & 0.27 & 10.95 \\
\hline & Increase in Peak Demand compared to & & & \\
\hline & Standalone $(\%)$ & & 0.11 & 8.07 \\
\hline \multirow{6}{*}{1} & Annual Demand (GWh/year) & 1.16 & 1.15 & 1.33 \\
\hline & Peak heating/cooling demand (kWh) & 536.6 & 537.5 & 582.3 \\
\hline & Increase in annual demand compared to & & & \\
\hline & Standalone $(\%)$ & & -0.26 & 13.22 \\
\hline & Increase in Peak Demand compared to & & & \\
\hline & Standalone $(\%)$ & & 0.17 & 7.85 \\
\hline
\end{tabular}

\subsection{2) Influence of wind speed and ambient temperature}

In order to assess the influence of the urban climate, the heating and cooling demand of buildings in the city center are taken into consideration. For these buildings, the annual heating demand obtained from Meteonorm is close to the value obtained from CIM, although the cooling demand shows a significant difference. The average cooling demand in the city center increases from 9.68 to $17.83 \mathrm{kWhm}^{-2}$ when changing the climatic data from Meteonorm to CIM. In order to assess this further, hourly demand profiles for three summer days $\left(21^{\text {st }}-23^{\text {rd }} \mathrm{June}\right)$ obtained using both CIM and Meteonorm are plotted in Fig. 6. The two demand profiles reveal that the increase in the demand for CIM is not uniform throughout the time line. Hence, moving from one to another creates a shift in the entire demand profile. A notable increase in the cooling demand is observed towards the peak, while it gradually decreases when moving away from the peak. For example, the peak demand is approximately doubled with the CIM meteorological data during a sunny day (average octas equals to 0), passing from $43 \mathrm{GWh}$ to $20 \mathrm{GWh}$ at 13:00 hours. A detailed explanation of this observation is presented in Section 5.2. Such extreme increases in hourly demand profile can have a notable impact on the energy system which is not reflected in the annual average demand discussed in detail in Section 5.2. 


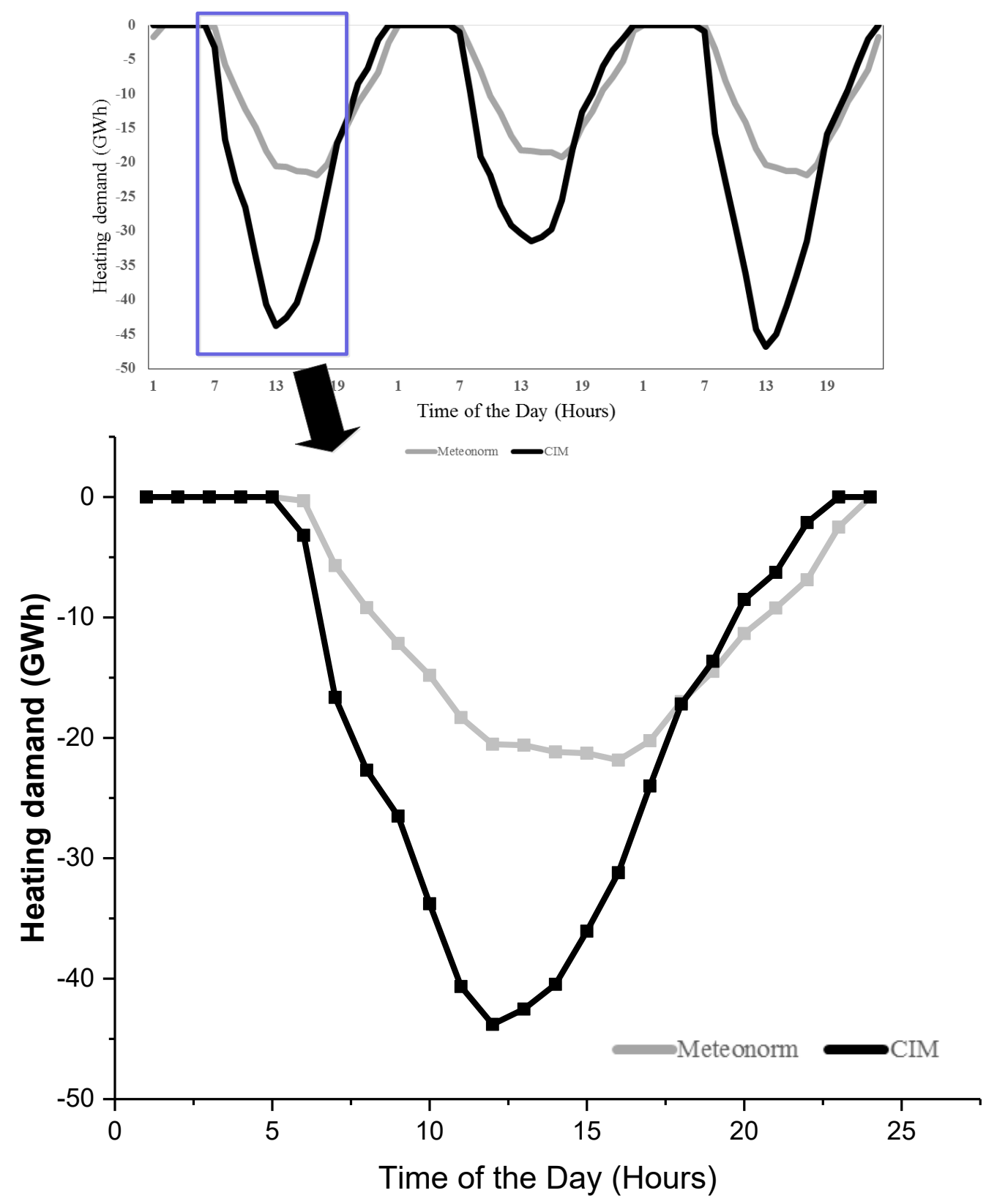

Fig. 6: Hourly demand for heating demand for Nablus center from 21st- 23rd June.

\section{2) Role of CIM in presenting higher resolution meteorological variables}

The main objective of coupling a building simulation tool with an urban climate model is to capture the influence of the presence of buildings in the urban context. In this context, CIM is used to calculate the high resolution vertical profiles of meteorological variables. These variables are then used as boundary conditions for CitySim, the building simulation tool. Hence, a detailed comparison of the temperature and wind profiles obtained from CIM with 
Meteonorm (simple meteorological data which do not consider the presence of buildings) can provide a better justification of the changes observed in heating and cooling demands in Section 5.1.

When analyzing the annual average wind speed and temperature, a difference in $1.5 \mathrm{~ms}^{-1}$ and $0.5^{\circ} \mathrm{C}$ is observed between CIM and Meteonorm respectively. However, this difference is trivial when compared to the changes observed for the building energy demand of the building stock at the center of Nablus (which can no longer explain the changes in energy demand). Hence, it is important to move into a higher temporal resolution. When moving into a monthly resolution, a difference of up to $1.5^{\circ} \mathrm{C}$ in temperature and of $2.2 \mathrm{~ms}^{-1}$ in wind speed is observed. However, when moving further up to an hourly scale, the temperature difference can reach up to $14^{\circ} \mathrm{C}$ as observed in Fig. 7 . By contrast, the wind speed difference is quite constant throughout the year (at the hourly temporal scale when compared to temperature) as shown in Fig. 8. The reason for this is that the drag force calculation does not change throughout the year since the density of obstacles remains the same and the reduction in the wind speed will consequently be more or less the same as well. CIM is using 1-D Navier-Stokes equations in this process, which can be improved by increasing the dimensions considered. This will result in introducing more fluctuations into the wind speed. However, it is noteworthy that there is a significant increase in the temperature during the summer time as opposed to the winter time for the Nablus case. In general, it can be concluded that CIM provides a better representation of the urban climate, which will help to get a better understanding of the meteorological variables. More importantly, the impact of urban climate is not linear, which will induce a direct shift in the energy demand.

It is interesting to assess the direct influence of urban microclimate on the cooling and heating demand at an hourly time resolution. To achieve this objective, air temperature values obtained from both CIM and Meteonorm are plotted along with the energy demand for a single day (in Fig. 9) in February. The peak demand is higher with the CIM weather profile during the daytime, and lower during the nighttime. This behavior is directly related to the air temperature, which is lower during the night time (by $2^{\circ} \mathrm{C}$ ) and higher during the daytime (by $5^{\circ} \mathrm{C}$ ). The temperatures of the surfaces within the urban environment are heated by the sunlight during the daytime, consequently increasing the temperature. Naturally, this behavior is evident during sunny days and limited for cloudy days. Additionally, the studied day is characterized by a moderate breeze during the daytime, according to the Meteonorm climatic data $\left(5.5 \mathrm{~ms}^{-1}\right)$, which is reduced to a gentle breeze according to the CIM meteorological data $\left(3.7 \mathrm{~ms}^{-1}\right)$. This can be explained using the concepts of urban heat islanding and cold air pools, which are 
however not the main focus of this study (interested readers are referred to Ref. [34] for a detailed description). As a result, the demand profile obtained using CIM has a peak demand higher than the one obtained using Meteonorm. At the same time, the lowest demand is also obtained for CIM, which will result in a higher fluctuation in the demand profile. Higher peak demand will result in requiring a larger system capacity while higher fluctuation in the demand profile will make the design and operation of the energy system more challenging. Hence, taking into account the urban climate will introduce more fluctuations and higher peak demands on a seasonal basis which will influence the energy system design. These issues are discussed in detail in the following section.

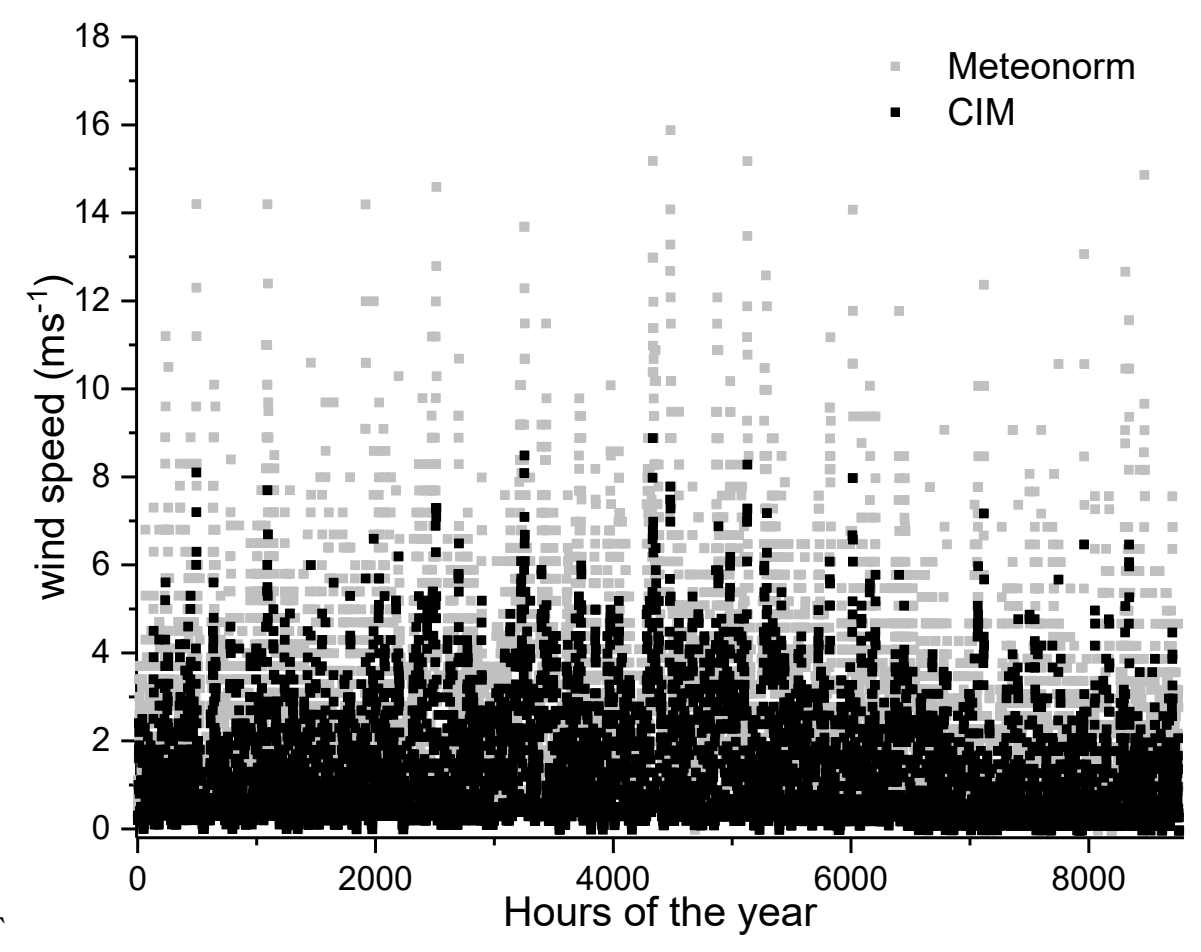

Fig. 7: Wind speed $\left(m s^{1}\right)$ obtained from Meteonorm (grey) and computed with CIM (black) for the dense scenario in Nablus 


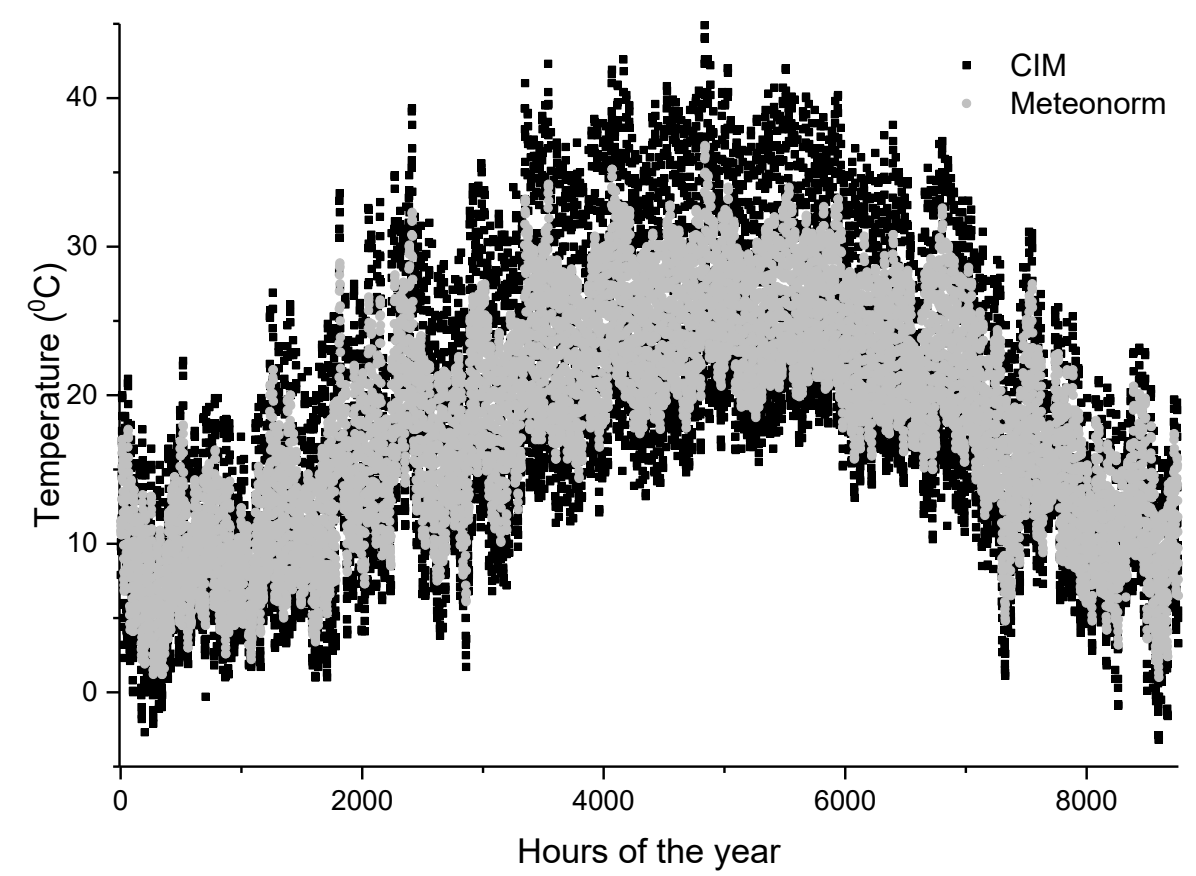

Fig. 8: Air temperature $\left({ }^{\circ} \mathrm{C}\right.$ ) obtained from Meteonorm (grey) and computed with CIM (black) for the dense scenario in Nablus

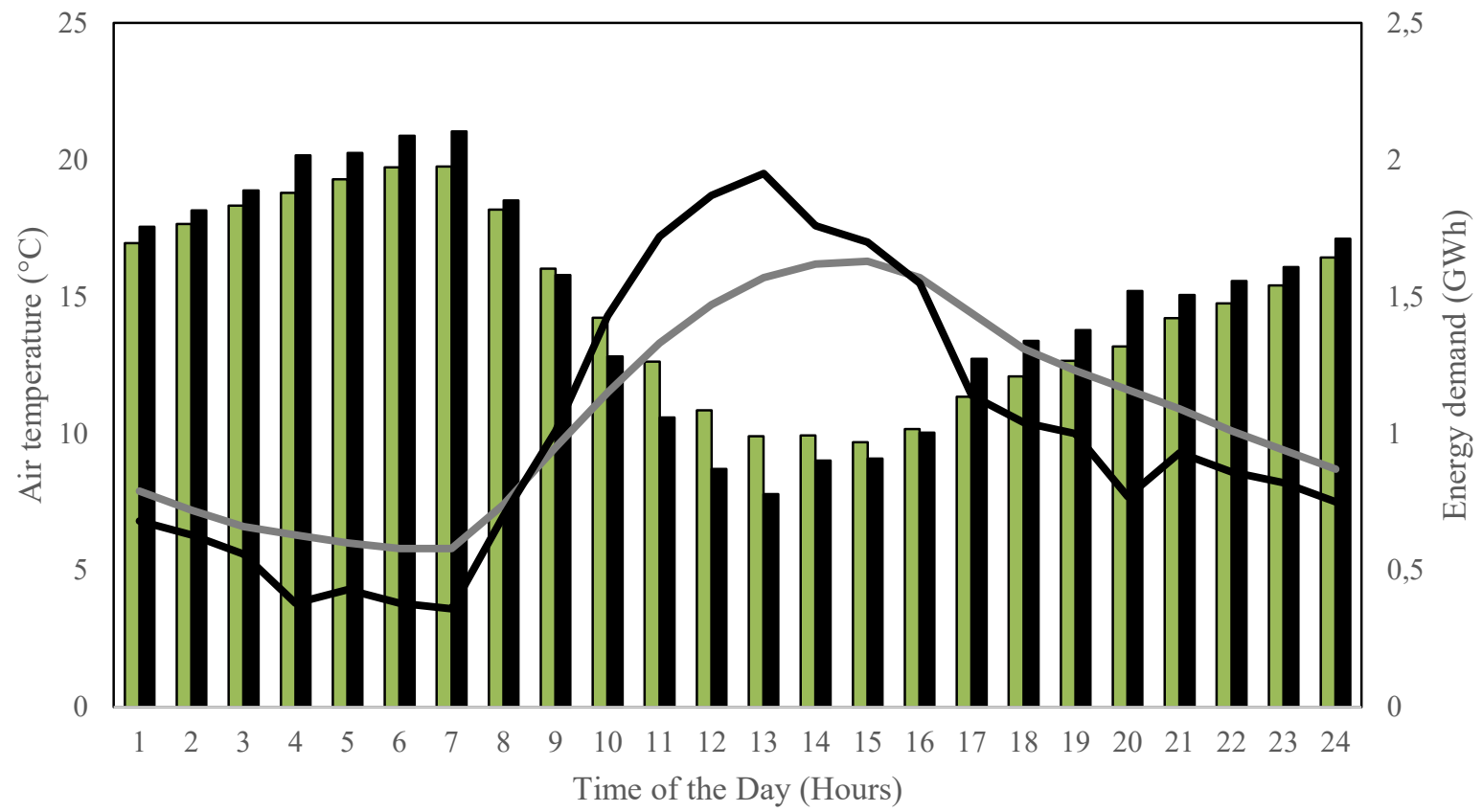

$\square$ Meteonorm demand CIM demand Meteonorm Air Temperature CIM Air Temperaure $\left({ }^{\circ} \mathrm{C}\right)$

Fig. 9: Air temperature and energy demand for the city of Nablus on $2^{\text {nd }}$ of February. 


\section{3) Influence of the urban climate on the energy system}

The notable influence of the urban climate on building energy demand is clearly reflected in Section 5.2 especially considering the dense areas. The effect of urban climate on the energy demand can have a notable impact on the performance of the energy system. Hence, it is interesting to conduct a comprehensive analysis on the impact of the microclimate on the energy system based on a set of performance indicators commonly used to assess the energy system. This is conducted in two steps in line with Section 5.1; the impact of shadowing and long-wave radiation at the building scale will be evaluated initially, followed by an assessment of the impact of the micro-climate. Building archetypes are used in this context to provide a normalized overview.

Energy systems are optimized considering NPV and GI as the objective functions taking the urban archetype of the center of Nablus. A detailed analysis of the impact of system autonomy on lifecycle cost and system configuration is given in Ref. [13]. Pareto fronts are obtained considering three scenarios i.e. neglecting the shadowing effect (both shadowing and long wave radiation) and adjusted wind speed (both wind speed and surface temperature) (Scenario "stand-alone"), considering the shadowing effect but neglecting the adjusted wind speed (Scenario Meteonorm) and considering both shadowing and adjusted wind speed (Scenario CIM) (Fig. 10). A clear Pareto front is observed for all three scenarios, which suggests that the NPV and GI level are conflicting objectives, for which it is difficult to reach to a single optimum solution considering both objectives. Pareto fronts obtained for Standalone and Meteonorm scenarios have objective function values quite close to each other except in a part of Region B (Fig. 10), where, Meteonorm presents marginally higher NPV compared to the Standalone scenario. However, a significant increase in objective function values is observed when moving to Scenario CIM which is due to the increase in energy demand as discussed in Section 5.2. The NPV increases by $20 \%$ in Region B, which decreases by 7-10 \% when moving into Region $\mathrm{C}$ while increasing the grid interactions. When moving into autonomous operation of the system, the Pareto fronts appear to be close to each other since the magnitude of the gradient is higher in this region. A closer look at the Pareto fronts shows that the difference in objective function values observed in Region B is maintained in Region A (in certain instances the difference increases as well). In conclusion, it can be stated that the increase in demand observed in building simulation is reflected and often magnified in the energy system design.

It is interesting to assess the impact of urban density on energy system design. To achieve this objective, energy system optimization is performed for the urban archetype representing the building density of the periphery of 
Nablus as the second case study. A third case study is introduced considering the future expansion of the city, in which the building density is expected to increase further. Both these case studies align with the case studies introduced in Section 5.1 (to quantify the effect of urban climate on the energy demand). A Pareto optimization is conducted considering NPV and GI and the objective functions for three scenarios illustrated before (i.e. Standalone, Meteonorm and CIM). Subsequently, the objective function values for each case study are normalized considering the three Pareto fronts obtained for each case study in order to make it easy for the readers to understand the deviation due to the building density (Fig. 11).

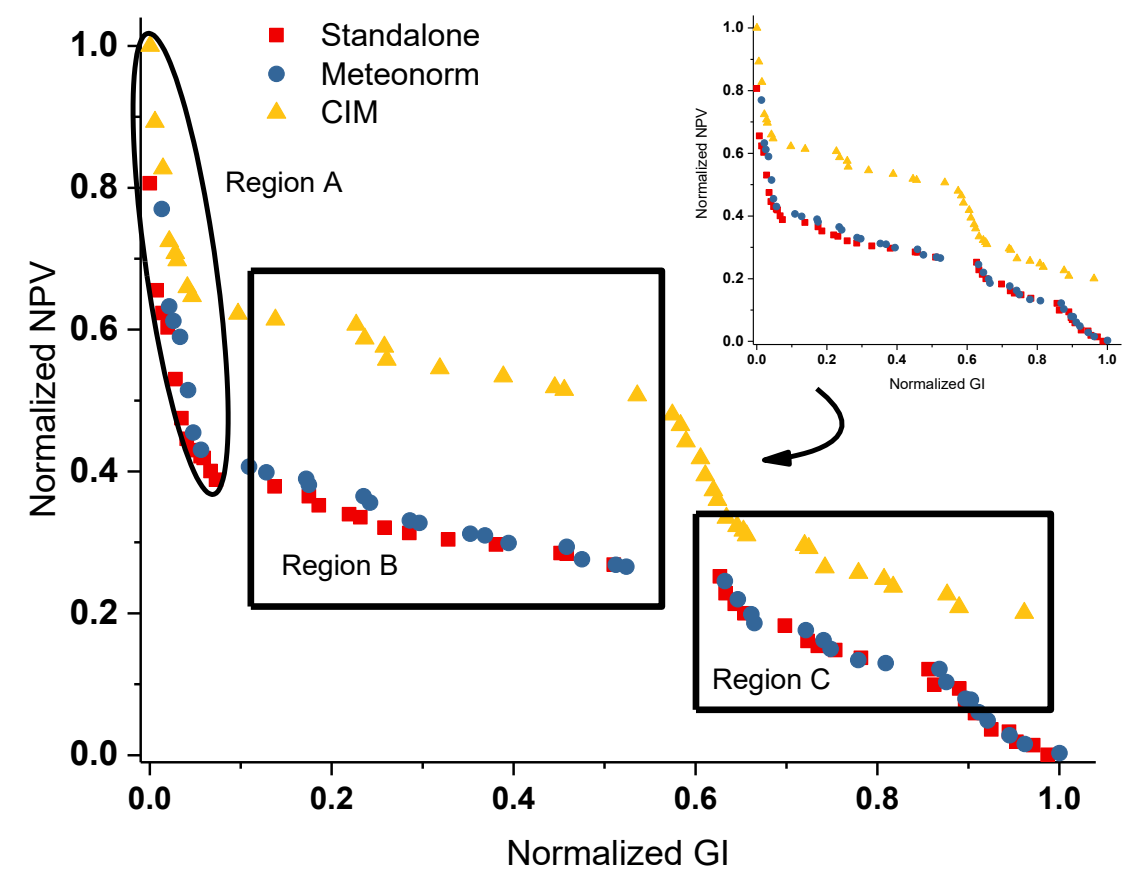

Fig. 10: Pareto front obtained considering NPV and GI as the objective functions. Values of the objective functions are normalized considering minimum and maximum objective function values obtained for the three Pareto fronts in order to simplify the analysis. 


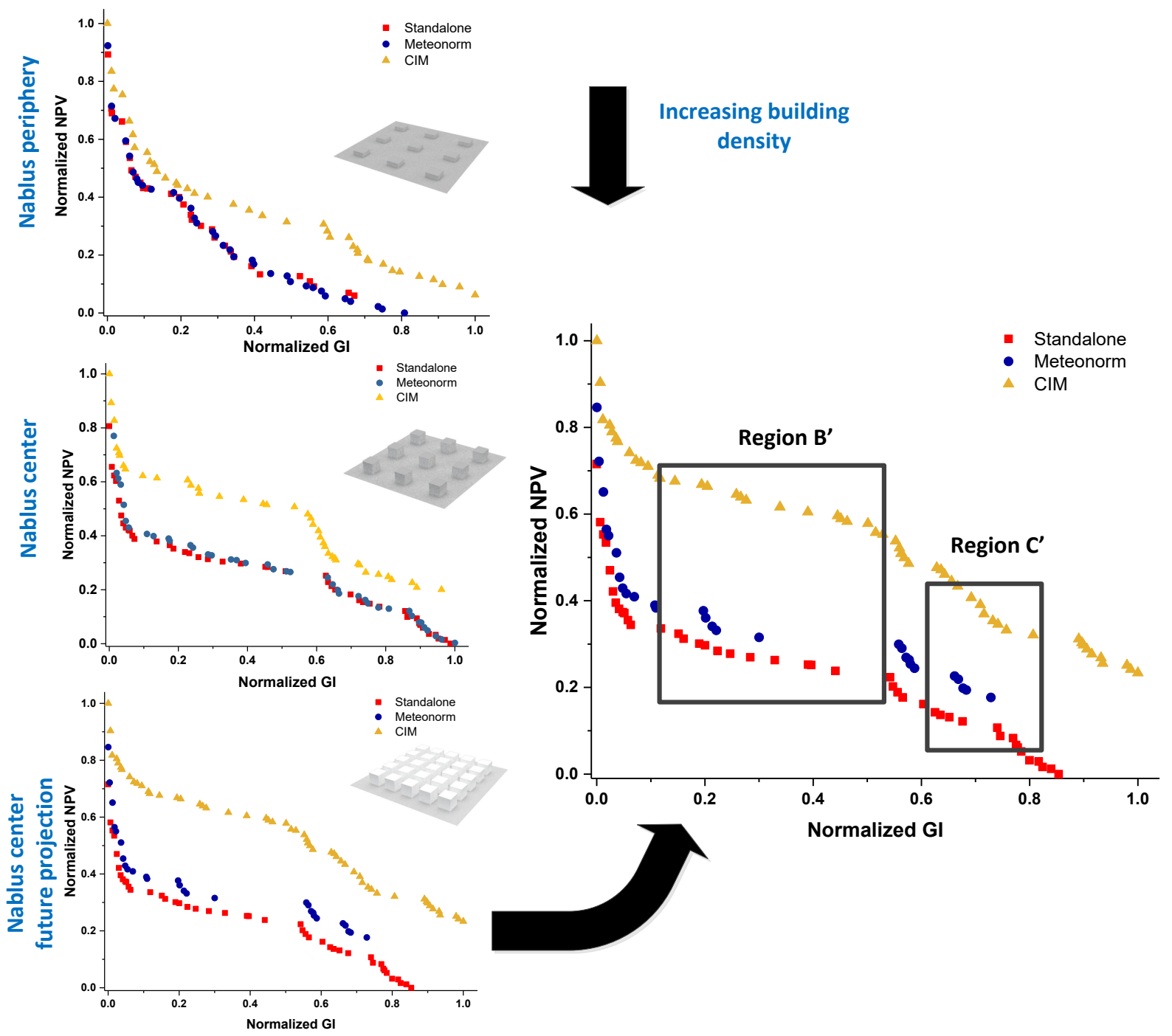

Fig. 11: Top to bottom plots in the left side of the figure presents the three Pareto fronts obtained for each case study i.e. Periphery of Nablus (PN), Center of Nablus (CN) and Future Center of Nablus. The three Pareto fronts obtained for Future Center of Nablus $(\mathrm{FCN})$ are enlarged on the right hand side image in order to elaborate the regions introduced in the figure

Pareto fronts obtained for the three case studies (Fig 11.) are used to get a qualitative understanding of the influence of urban climate in the context of energy system sizing (which is assessed quantitatively in Section 5.4). When comparing the three case studies, it is observed that the Pareto fronts for Meteonorm and Standalone follow close to each other for both the periphery and the center of Nablus (discussed previously in this section). However, a clear 
separation of these two Pareto fronts is observed when moving into the future center of Nablus, which takes into account an increase in the objective function values of up to $10 \%$ (future center of Nablus-CIM). These results show that neglecting the influence of shadowing and long wave radiation may lead to a deviation in NPV of up to $10 \%$. The deviation observed can be further increased in cities that have skyscrapers and much higher building densities. The influence of building density on energy system sizing can be clearly understood when comparing standalone and CIM scenarios for future center of Nablus. The differences in the objective function values (stand alone and CIM) increase by up to $40 \%$ when considering the future center of Nablus which is on average a $20 \%$ increase when compared to buildings in the periphery of Nablus. These results show that the urban climate can have a notable influence on the energy system design process, especially in highly dense cities.

\section{4) Consequences of neglecting urban climate in energy system sizing}

A quantitative analysis is conducted in this section to understand the influence of urban climate (extending the qualitative analysis conducted in Section 5.3) and the consequences of neglecting it during the energy system design process. Pareto solutions are taken for further assessment from the three Pareto fronts of the future center of Nablus which presented the highest deviation in objective function values.

Four sets of design solutions (with similar grid purchase values) are taken from the three Pareto fronts and tabulated in Table 3. When considering each set, it is clear that the NPV has increased by $3-6 \%$ when moving from the Standalone to the Meteonorm scenario while it increases by more than $20 \%$ when moving from the standalone scenario to CIM. For example, NPV has increased by $4.8 \%$ when moving from 1-SA to 1-MET while it has increased by $20.3 \%$ when moving from 1 -SA to 1 -CIM. These quantitative values align with the qualitative explanation provided in Section 5.3. The increase in NPV is well beyond the increase in the demand. It can be concluded that increase in demand as well as the fluctuations introduced to the demand profile due to the urban climate result in a notable increase in NPV.

When analyzing Table 3 further, it is clear that both the ICG contribution and capacity follows the pattern of NPV when moving from the standalone to the CIM scenario. The percentage contribution of the ICG increases by 3-10\% when moving from the standalone to the CIM scenario. For example, ICG generation increases by $3.2 \%$ when 
moving from 4-CIM to 4-SA while it increases by $10 \%$ when moving from 1-SA to 1-CIM. A clear pattern is not observed for system configuration except for the ICG capacity when moving from the standalone to the CIM scenario. As discussed in Section 5.1, the increase in demand is not uniform throughout the year when moving from the standalone to the CIM scenario. As a result, a uniform increase in renewable energy components, energy storage and dispatchable source is not observed. A notable increase in daily peaks is observed in the demand curve which results in introducing more fluctuations into the demand profile calling for support from the dispatchable source whenever the grid is not catering the mismatch. This results in higher ICG capacity and contribution when moving from the standalone scenario to CIM. In general, the changes brought to the demand pattern due to the urban climate result in changes in the energy system configuration.

The effect of urban climate is considered in CIM and neglected in the standalone scenario. Where urban climate is not considered, the system will be designed based on the demand profile obtained for the standalone scenario. The system designed for the standalone scenario will have to cater the demand profile of CIM due to the effect of urban climate which is not considered at the design point. This will result in a performance gap. The performance gap clearly presents the consequences of not considering the urban climate at an early point of energy system design. To assess the impact further, performances of the four energy systems obtained for the standalone scenario (already presented in Table 3) are evaluated considering the demand profile of the CIM scenario (for the future center of Nablus). When analyzing the results, a notable performance gap can be observed for all the performance indicators (Table 4). NPV increase by 5-8\% while grid dependency increases by up to $57 \%$. More importantly, all the design solutions violate the constraint on power supply reliability set at the formulation of the optimization problem. A significant increase in ICG contribution is observed due to the increase in the peak demand as discussed before. In general, it can be concluded that neglecting the urban climate may lead to a notable performance gap. More importantly, energy systems fail to maintain the reliability of the power supply which is considered as an important constraint in design optimization.

\section{5) Overall computational time required}

Computational time required for the overall process and the additional computational burden due to the consideration of urban climate is an important aspect which needs to be evaluated. Simulations are run on a single processor $(1.2 \mathrm{GHz})$ for each scenario and for each city for one full year (8760 time step) for both CIM and CitySim. 
The energy hub model is implemented in Intel(R) Core(TM) i7-6700-3.40 GHz CPU. CIM simulations are more computationally extensive compared to the CitySim ones (Table 5). Since CIM is dependent on the number of vertical levels, it takes significantly more time to run for a domain with higher buildings. Higher buildings imply that there are additional cells so that a surface layer can be developed above the displacement height. It is clear that CIM adds an additional computational load to energy system sizing, extending the computational time by approximately four times. However, the extension of the computational time can be easily justified when considering the improvements obtained in the energy system design.

Table 5: Computational time in seconds for each simulation for CIM, CitySim and energy hub model

\begin{tabular}{llll}
\hline & CIM (s) & CitySim(s) & Energy hub model (s) \\
\hline Center of city & 39752 & 252 & 7160 \\
Periphery of city & 39759 & 237 & 7320 \\
\hline
\end{tabular}

\section{Conclusions and future perspectives}

Providing sustainable energy solutions to rapidly growing cities is a challenging task. Urban energy systems play a major role in this context. Computational platforms combining different fields of expertise will help the energy engineers to face this challenge. This study highlights the importance of filling the research gap by combining energy system optimization with building simulation and urban climate modeling. The complexity of modeling the urban climate and subsequent coupling with a bottom up building simulation tool and an energy system designing tool make it difficult to develop a computational platform that can bridge all these elements. This study presents an effective way to address the problem by combining CIM, CitySim and an energy hub model as a computational platform to address the aforementioned research gap.

Results of the study reveal that the response of a cluster of buildings is different from that of a single building. Therefore, it is difficult to make predictions based on the performance of a single standalone building due to the interaction among the buildings and the micro-climate. The study shows that more fluctuations in demand profile (heating and cooling) are observed when moving from standalone buildings to dense urban areas. This makes it more challenging to design urban energy systems. Furthermore, both peak and annual energy demand can increase respectively by $13 \%$ to $18 \%$ when considering urban climate. All these results emphasize that the urban climate plays a major role in energy demand. Therefore, it is important to look at the energy efficiency of an entire building 
stock at neighborhood or urban scale considering the interactions among buildings and the micro-climate and not to limit the efforts to energy efficiency at building scale.

The influence of urban climate on energy demand has a significant impact on the energy system. The increase observed in peak and annual demand results in an increase in NPV of the energy system. NPV of the energy system increases up to $40 \%$ when considering the effect of urban climate in highly dense urban scenarios. Therefore, neglecting the influence of urban climate can result in a significant performance gap for all the performance indicators of the energy system, which can reach up to $50 \%$ in certain scenarios. This highlights the importance of developing a computational platform combining urban climate, building simulation and energy system optimization. Furthermore, both active and passive strategies should be introduced to minimize the adverse impacts due to urban climate. Introducing green areas and water bodies into the cities, building renovation and green roofs and facades would be promising remedies [67]. The computational platform introduced in this study should be extended further to accommodate the influence of the aforementioned factors. In addition, it is important to evaluate the effectiveness of different urban configurations in order to minimize the the adverse impact of increasing urban densities. In conclusion, the impact of the urban morphology on the energy systems should be carefully considered during the urban planning process. A computational platform introduced in this study can be immensely helpful in this context. However, it is important to extend the boundaries of the computational platform to consider other aspects such as transportation, outdoor comfort etc. which will help the urban planners to produce better designs.

\section{Acknowledgements}

Authors would like to acknowledge the support from Professor Sameh Monna from An-Najah National University, Palestine, Miss Hirushie Karunathilake from University of British Columbia, Canada and Mrs. Barbara Smith from LESO-PB, EPFL, Switzerland. This research has been financed partly by the EPFL Middle East and partly by Swiss

Competence Center for Energy Research SCCER FEEB\&D of the Swiss Innovation Agency Innosuisse (CTI.2014.0119). 
Table 3: Comparison of the three scenarios by taking Pareto solutions that are having grid purchase values close to each other

\begin{tabular}{|c|c|c|c|c|c|c|c|c|c|c|c|}
\hline Scenario $^{1}$ & Name & $\begin{array}{l}\text { NPV } \\
\left(\times 10^{6}\right. \\
\text { Euro) }\end{array}$ & $\begin{array}{c}\text { Grid } \\
\text { Purchase } \\
\text { (MWh) }\end{array}$ & $\begin{array}{l}\text { Export } \\
\text { to the } \\
\text { grid }(\%)\end{array}$ & $\begin{array}{c}\mathrm{ICG} \\
\text { generation } \\
(\%)\end{array}$ & $\begin{array}{c}\text { PV panel } \\
\text { capacity } \\
(\mathrm{kVA})\end{array}$ & $\begin{array}{l}\text { Wind } \\
\text { turbine } \\
\text { capacity } \\
(\mathrm{kVA})\end{array}$ & $\begin{array}{c}\text { Total } \\
\text { renewable } \\
\text { capacity } \\
(\mathrm{kVA}) \\
\end{array}$ & $\begin{array}{c}\mathrm{PV} \\
\text { capacity } \\
(\%)\end{array}$ & $\begin{array}{c}\text { Battery bank } \\
\text { capacity } \\
(\mathrm{kWh})\end{array}$ & $\begin{array}{c}\mathrm{ICG} \\
\text { capacity } \\
(\mathrm{kVA})\end{array}$ \\
\hline SA & $1-\mathrm{SA}$ & 4.80 & 5.74 & 53.05 & 26.33 & 210 & 680 & 890 & 23.60 & 20 & 100 \\
\hline MET & 1-MET & 5.03 & 5.27 & 45.32 & 32.77 & 155 & 560 & 715 & 21.68 & 19 & 120 \\
\hline CIM & 1-CIM & 5.77 & 5.68 & 42.18 & 36.42 & 150 & 600 & 750 & 20.00 & 19 & 140 \\
\hline $\mathrm{SA}$ & $2-\mathrm{SA}$ & 4.41 & 23.84 & 43.77 & 28.79 & 140 & 560 & 700 & 20.00 & 15 & 100 \\
\hline MET & 2-MET & 4.54 & 22.11 & 48.16 & 30.02 & 170 & 560 & 730 & 23.29 & 19 & 100 \\
\hline CIM & 2-CIM & 5.44 & 22.89 & 47.03 & 37.03 & 175 & 580 & 755 & 23.18 & 4 & 140 \\
\hline SA & $3-\mathrm{SA}$ & 4.21 & 55.59 & 46.97 & 25.17 & 140 & 580 & 720 & 19.44 & 15 & 100 \\
\hline MET & 3-MET & 4.35 & 58.74 & 42.83 & 27.16 & 130 & 560 & 690 & 18.84 & 19 & 100 \\
\hline CIM & 3-CIM & 5.22 & 66.12 & 47.26 & 31.41 & 170 & 580 & 750 & 22.67 & 4 & 140 \\
\hline $\mathrm{SA}$ & 4-SA & 3.90 & 117.09 & 47.18 & 17.08 & 155 & 540 & 695 & 22.30 & 19 & 80 \\
\hline MET & 4-MET & 4.14 & 113.93 & 51.06 & 18.08 & 210 & 540 & 750 & 28.00 & 20 & 80 \\
\hline CIM & 4-CIM & 4.84 & 111.82 & 52.60 & 21.33 & 255 & 540 & 795 & 32.08 & 20 & 100 \\
\hline
\end{tabular}

1) SA, MET and CIM denote Standalone, Meteonorm and CIM scenarios

Table 4: Performance gap due to neglecting the urban climate in energy system optimization

\begin{tabular}{|c|c|c|c|c|c|c|c|c|c|}
\hline Name & Demand & $\begin{array}{c}\text { NPV } \\
\left(\times 10^{6} \text { Euro) }\right.\end{array}$ & $\begin{array}{l}\text { Increase in } \\
\operatorname{NPV}(\%)\end{array}$ & $\begin{array}{l}\text { Grid Purchase } \\
\text { (MWh) }\end{array}$ & $\begin{array}{l}\text { Increase in } \\
\text { Grid purchase }\end{array}$ & $\begin{array}{l}\text { Export to the } \\
\text { grid (\%) }\end{array}$ & $\begin{array}{c}\text { ICG generation } \\
(\%)\end{array}$ & $\begin{array}{l}\text { Increase in ICG } \\
\text { Generation (\%) }\end{array}$ & $\begin{array}{c}\text { Constraint } \\
\text { violation }\end{array}$ \\
\hline $1-\mathrm{SA}$ & $\mathrm{SA}$ & 4.80 & \multirow{2}{*}{5.34} & 5.74 & \multirow{2}{*}{57.67} & \multirow{2}{*}{-11.50} & 26.33 & \multirow{2}{*}{15.19} & no \\
\hline 1-SA-R & FCN-CIM & 5.07 & & 13.57 & & & 31.04 & & yes \\
\hline 2-SA & SA & 4.41 & \multirow{2}{*}{6.87} & 23.84 & \multirow{2}{*}{35.65} & \multirow{2}{*}{-17.46} & 28.79 & \multirow{2}{*}{14.74} & no \\
\hline 2-SA-R & FCN-CIM & 4.73 & & 37.05 & & & 33.77 & & yes \\
\hline $3-\mathrm{SA}$ & SA & 4.21 & \multirow{2}{*}{7.61} & 55.59 & \multirow{2}{*}{20.37} & \multirow{2}{*}{-19.34} & 25.17 & \multirow{2}{*}{16.15} & no \\
\hline 3-SA-R & FCN-CIM & 4.56 & & 69.81 & & & 30.01 & & yes \\
\hline $4-\mathrm{SA}$ & SA & 3.90 & \multirow{2}{*}{7.48} & 117.09 & \multirow{2}{*}{15.95} & \multirow{2}{*}{-17.25} & 17.08 & \multirow{2}{*}{17.8} & no \\
\hline 4-SA-R & FCN-CIM & 4.22 & & 22.89 & & & 37.03 & & yes \\
\hline
\end{tabular}




\section{Nomenclature}

$A_{x}^{S P V}$ Area of SPV panel

CFD computational fluid dynamic

CIM Canopy Interface Model

$E_{t}^{D}$ demand of the energy system

$E_{t}^{I G}$ energy imported from the grid

$\tilde{E_{t}^{W}}\left(\mathrm{v}_{\mathrm{t}}\right)$ wind power generation from a single wind turbine

FOM fixed operation and maintenance cost

$f_{m}^{s}$ momentum fluxes

$f_{\theta}^{S}$ heat fluxes

$G_{t}^{\beta}$, global solar irradiation on the tilted PV panel

$h_{t}^{c, i}$ convective heat transfer coefficient

ICG internal combustion generator

NPV Net Present Value

$N^{S P V}$ number of PV panels

$\mathrm{N}^{\mathrm{w}}$ number of wind turbines in the system

MEH multi energy hub

\section{MVG Medium Voltage Grid}

OM operation and maintenance cost

Pr Prandtl number

$Q_{t}^{l w, i}$ longwave flux

SPV Solar PV panels

SRA Simplified Radiosity Algorithm

$t$ time step

TKE turbulent kinetic energy

UHI urban heat islanding

$u$ mean horizontal wind component

VOM variable operational and maintenance cost

$x^{s p v}$ Type of SPV panel

$\theta_{t}^{s, i}$ surface temperature

$\theta_{t}^{\text {air }}$ is the air temperature

$\zeta$ shading factor

$\eta_{t, x^{S P V}}^{S P V}$ efficiency of the SPV panel

$\eta^{\text {w-losses }}$ power losses in wind turbines

\section{References}

[1] David Satterthwaite, "The implications of population growth and urbanization for climate change," Environ. Urban., vol. 21, no. 2, pp. 545-567, Oct. 2009.

[2] R. Madlener and Y. Sunak, "Impacts of urbanization on urban structures and energy demand: What can we learn for urban energy planning and urbanization management?," Sustain. Cities Soc., vol. 1, no. 1, pp. 45-53, Feb. 2011.

[3] H. Lund and B. V. Mathiesen, "Energy system analysis of $100 \%$ renewable energy systems-The case of Denmark in years 2030 and 2050," Energy, vol. 34, no. 5, pp. 524-531, May 2009.

[4] B. Ćosić, G. Krajačić, and N. Duić, "A 100\% renewable energy system in the year 2050: The case of Macedonia," Energy, vol. 48, no. 1, pp. 80-87, Dec. 2012.

[5] M. Amado, F. Poggi, and A. R. Amado, "Energy efficient city: A model for urban planning," Sustain. Cities Soc., vol. 26, no. Supplement C, pp. 476-485, Oct. 2016. 
[6] Z. Shi, J. A. Fonseca, and A. Schlueter, "A review of simulation-based urban form generation and optimization for energy-driven urban design," Build. Environ., vol. 121, no. Supplement C, pp. 119-129, Aug. 2017.

[7] N. Mohajeri, G. Upadhyay, A. Gudmundsson, D. Assouline, J. Kämpf, and J.-L. Scartezzini, "Effects of urban compactness on solar energy potential," Renew. Energy, vol. 93, pp. 469-482, Aug. 2016.

[8] S. Fazlollahi, G. Becker, A. Ashouri, and F. Maréchal, "Multi-objective, multi-period optimization of district energy systems: IV - A case study," Energy, vol. 84, pp. 365-381, May 2015.

[9] G. Mavromatidis, K. Orehounig, and J. Carmeliet, "Evaluation of photovoltaic integration potential in a village," Sol. Energy, vol. 121, pp. 152-168, Nov. 2015.

[10] K. Orehounig, G. Mavromatidis, R. Evins, V. Dorer, and J. Carmeliet, "Towards an energy sustainable community: An energy system analysis for a village in Switzerland," Energy Build., vol. 84, pp. 277-286, Dec. 2014.

[11] H. Karunathilake, P. Perera, R. Ruparathna, K. Hewage, and R. Sadiq, "Renewable energy integration into community energy systems: A case study of new urban residential development," J. Clean. Prod., Oct. 2016.

[12] J. Keirstead, M. Jennings, and A. Sivakumar, "A review of urban energy system models: Approaches, challenges and opportunities," Renew. Sustain. Energy Rev., vol. 16, no. 6, pp. 3847-3866, Aug. 2012.

[13] A. T. D. Perera, V. M. Nik, D. Mauree, and J.-L. Scartezzini, "Electrical hubs: An effective way to integrate non-dispatchable renewable energy sources with minimum impact to the grid," Appl. Energy, vol. 190, pp. 232-248, Mar. 2017.

[14] M. L. Guen, L. Mosca, A. T. D. Perera, S. Coccolo, N. Mohajeri, and J.-L. Scartezzini, "Improving the energy sustainability of a Swiss village through building renovation and renewable energy integration," Energy Build., vol. 158, no. Supplement C, pp. 906-923, Jan. 2018.

[15] B. Morvaj, R. Evins, and J. Carmeliet, "Decarbonizing the electricity grid: The impact on urban energy systems, distribution grids and district heating potential," Appl. Energy, vol. 191, pp. 125-140, Apr. 2017.

[16] A. T. D. Perera, A. N. Madusanka, R. A. Attalage, and K. K. C. K. Perera, "A multi criterion analysis for renewable energy integration process of a standalone hybrid energy system with internal combustion generator," J. Renew. Sustain. Energy, vol. 7, no. 4, p. 043128, Jul. 2015.

[17] S. Fazlollahi, G. Becker, and F. Maréchal, "Multi-objectives, multi-period optimization of district energy systems: III. Distribution networks," Comput. Chem. Eng., vol. 66, pp. 82-97, Jul. 2014.

[18] S. Fazlollahi, P. Mandel, G. Becker, and F. Maréchal, "Methods for multi-objective investment and operating optimization of complex energy systems," Energy, vol. 45, no. 1, pp. 12-22, Sep. 2012.

[19] B. Morvaj, R. Evins, and J. Carmeliet, "Optimization framework for distributed energy systems with integrated electrical grid constraints,” Appl. Energy, vol. 171, no. Supplement C, pp. 296-313, Jun. 2016.

[20] A. Maroufmashat et al., "Modeling and optimization of a network of energy hubs to improve economic and emission considerations," Energy, vol. 93, no. Part 2, pp. 2546-2558, Dec. 2015.

[21] R. Baños, F. Manzano-Agugliaro, F. G. Montoya, C. Gil, A. Alcayde, and J. Gómez, "Optimization methods applied to renewable and sustainable energy: A review," Renew. Sustain. Energy Rev., vol. 15, no. 4, pp. 17531766, May 2011.

[22] D. Connolly, H. Lund, B. V. Mathiesen, and M. Leahy, "A review of computer tools for analysing the integration of renewable energy into various energy systems," Appl. Energy, vol. 87, no. 4, pp. 1059-1082, Apr. 2010.

[23] A. H. Fathima and K. Palanisamy, "Optimization in microgrids with hybrid energy systems - A review," Renew. Sustain. Energy Rev., vol. 45, pp. 431-446, May 2015.

[24] C. Ratti, N. Baker, and K. Steemers, "Energy consumption and urban texture," Energy Build., vol. 37, no. 7, pp. 762-776, Jul. 2005.

[25] L. Frayssinet, L. Merlier, F. Kuznik, J.-L. Hubert, M. Milliez, and J.-J. Roux, "Modeling the heating and cooling energy demand of urban buildings at city scale," Renew. Sustain. Energy Rev., vol. 81, no. Part 2, pp. 2318-2327, Jan. 2018.

[26] P. Moonen, T. Defraeye, V. Dorer, B. Blocken, and J. Carmeliet, "Urban Physics: Effect of the micro-climate on comfort, health and energy demand," Front. Archit. Res., vol. 1, no. 3, pp. 197-228, Sep. 2012.

[27] E. Bozonnet, R. Belarbi, and F. Allard, "Thermal Behaviour of buildings: modelling the impact of urban heat island," J. Harbin Inst. Technol., vol. 14, no. Sup., pp. 19-22, 2007.

[28] R. Evins, "Multi-level optimization of building design, energy system sizing and operation," Energy.

[29] R. Wu, G. Mavromatidis, K. Orehounig, and J. Carmeliet, "Multiobjective optimisation of energy systems and building envelope retrofit in a residential community," Appl. Energy, vol. 190, pp. 634-649, Mar. 2017. 
[30] J. A. Fonseca, T.-A. Nguyen, A. Schlueter, and F. Marechal, "City Energy Analyst (CEA): Integrated framework for analysis and optimization of building energy systems in neighborhoods and city districts," Energy Build., vol. 113, no. Supplement C, pp. 202-226, Feb. 2016.

[31] J. A. Fonseca and A. Schlueter, "Integrated model for characterization of spatiotemporal building energy consumption patterns in neighborhoods and city districts," Appl. Energy, vol. 142, no. Supplement C, pp. 247265, Mar. 2015.

[32] D. Mauree, N. Blond, M. Kohler, and A. Clappier, "On the Coherence in the Boundary Layer: Development of a Canopy Interface Model," Front. Earth Sci., vol. 4, 2017.

[33] D. Mauree, D. Sang-Hoon Lee, E. Naboni, S. Coccolo, and J.-L. Scartezzini, "Localized meteorological variables influence at the early design stage," Energy Procedia, vol. 122, no. Supplement C, pp. 325-330, Sep. 2017.

[34] D. Mauree, S. Coccolo, J. Kaempf, and J.-L. Scartezzini, "Multi-scale modelling to evaluate building energy consumption at the neighbourhood scale," PLOS ONE, 2017.

[35] D. Mauree, A. T. D. Perera, and J.-L. Scartezzini, "Influence of Buildings Configuration on the Energy Demand and Sizing of Energy Systems in an Urban Context," Energy Procedia, vol. 142, pp. 2648-2654, Dec. 2017.

[36] D. Mauree, J. H. Kämpf, and J.-L. Scartezzini, "Multi-scale modelling to improve climate data for building energy models," in Proceedings of the 14th International Conference of the International Building Performance Simulation Association, Hyderabad, 2015.

[37] M. Manfren, P. Caputo, and G. Costa, "Paradigm shift in urban energy systems through distributed generation: Methods and models," Appl. Energy, vol. 88, no. 4, pp. 1032-1048, Apr. 2011.

[38] D. Mauree, "Development of a multi-scale meteorological system to improve urban climate modeling," Université de Strasbourg, 2014.

[39] “CitySim Software | LESO-PB.” [Online]. Available: http://citysim.epfl.ch/. [Accessed: 25-Nov-2015].

[40] D. Robinson et al., "SUNtool - A new modelling paradigm for simulating and optimising urban sustainability," Sol. Energy, vol. 81, no. 9, pp. 1196-1211, Sep. 2007.

[41] E. Walter and J. H. Kämpf, "A verification of CitySim results using the BESTEST and monitored consumption values," Proc. 2nd Build. Simul. Appl. Conf., pp. 215-222, 2015.

[42] D Robinson and A Stone, "A simplified radiosity algorithm for general urban radiation exchange," Build. Serv. Eng. Res. Technol., vol. 26, no. 4, pp. 271-284, Nov. 2005.

[43] A. T. D. Perera, V. M. Nik, D. Mauree, and J.-L. Scartezzini, "An integrated approach to design site specific distributed electrical hubs combining optimization, multi-criterion assessment and decision making," Energy, vol. 134, pp. 103-120, Sep. 2017.

[44] J. Remund, Quality of Meteonorm Version 6.0. 2008.

[45] C. Ratti, D. Raydan, and K. Steemers, "Building form and environmental performance: archetypes, analysis and an arid climate," Energy Build., vol. 35, no. 1, pp. 49-59, Jan. 2003.

[46] H. Sanaieian, M. Tenpierik, K. van den Linden, F. Mehdizadeh Seraj, and S. M. Mofidi Shemrani, "Review of the impact of urban block form on thermal performance, solar access and ventilation," Renew. Sustain. Energy Rev., vol. 38, pp. 551-560, Oct. 2014.

[47] T. R. Oke, "The energetic basis of the urban heat island," Q. J. R. Meteorol. Soc., vol. 108, no. 455, pp. 1-24, Jan. 1982.

[48] D. Mauree, N. Blond, M. Kohler, and A. Clappier, "On the Coherence in the Boundary Layer: Development of a Canopy Interface Model," Front. Earth Sci., vol. 4, 2017.

[49] C. Skamarock et al., "A Description of the Advanced Research WRF Version 3," 2008.

[50] A. Monin and A. Yaglom, "Statistical fluid dynamics," Vol II MIT Press Camb., 1971.

[51] C. H. B. Priestley and W. C. Swinbank, "Vertical Transport of Heat by Turbulence in the Atmosphere," Proc. R. Soc. Lond. Ser. Math. Phys. Sci, vol. 189, no. 1019, pp. 543-561, 1947.

[52] D. Mauree, S. Coccolo, S. Monna, J. Kämpf, and J.-L. Scartezzini, "On the impact of local climatic conditions on urban energy use: A case study," Proc. PLEA 2016, 2016.

[53] S. Coccolo, D. Mauree, J. Kämpf, and J.-L. Scartezzini, "Integration of outdoor human comfort in a building energy simulation database using CityGML Energy Ade," Expand. Boundaries - Syst. Think. Built Environ. Proc. Sustain. Built Environ. SBE Reg. Conf. Zurich 2016, 2016.

[54] D. Mauree, S. Coccolo, J. Kämpf, and J.-L. Scartezzini, "Multi-scale modelling to assess human comfort in urban canyons," presented at the Expanding Boundaries - Systems Thinking in the Built Environment Proceedings of the Sustainable Built Environment (SBE) Regional Conference Zurich 2016. 
[55] F. Salamanca, A. Krpo, A. Martilli, and A. Clappier, "A new building energy model coupled with an urban canopy parameterization for urban climate simulations - part I. formulation, verification, and sensitivity analysis of the model," Theor. Appl. Climatol., vol. 99, no. 3-4, pp. 331-344, Jan. 2010.

[56] D. Mauree, S. Coccolo, J. Kaempf, and J.-L. Scartezzini, "Multi-scale modelling to evaluate building energy consumption at the neighbourhood scale," PLOS ONE, vol. 12, no. 9, p. e0183437, Sep. 2017.

[57] A. Martilli, A. Clappier, and M. W. Rotach, "An Urban Surface Exchange Parameterisation for Mesoscale Models," Bound.-Layer Meteorol., vol. 104, no. 2, pp. 261-304, 2002.

[58] A. Krpo, F. Salamanca, A. Martilli, and A. Clappier, "On the Impact of Anthropogenic Heat Fluxes on the Urban Boundary Layer: A Two-Dimensional Numerical Study," Bound.-Layer Meteorol., vol. 136, no. 1, pp. 105-127, Jul. 2010.

[59] M. Geidl and G. Andersson, "Optimal Power Flow of Multiple Energy Carriers," IEEE Trans. Power Syst., vol. 22, no. 1, pp. 145-155, Feb. 2007.

[60] M. Mohammadi, Y. Noorollahi, B. Mohammadi-ivatloo, and H. Yousefi, "Energy hub: From a model to a concept - A review," Renew. Sustain. Energy Rev., vol. 80, no. Supplement C, pp. 1512-1527, Dec. 2017.

[61] A. A. Elmokadem, N. A. Megahed, and D. S. Noaman, "Towards a computer program for building-integrated wind technologies," Energy Build., vol. 117, no. Supplement C, pp. 230-244, Apr. 2016.

[62] W. Durisch, B. Bitnar, J.-C. Mayor, H. Kiess, K. Lam, and J. Close, "Efficiency model for photovoltaic modules and demonstration of its application to energy yield estimation," Sol. Energy Mater. Sol. Cells, vol. 91, no. 1, pp. 79-84, Jan. 2007.

[63] A. T. D. Perera, D. M. I. J. Wickremasinghe, D. V. S. Mahindarathna, R. A. Attalage, K. K. C. K. Perera, and E. M. Bartholameuz, "Sensitivity of internal combustion generator capacity in standalone hybrid energy systems," Energy, vol. 39, no. 1, pp. 403-411, Mar. 2012.

[64] A. T. D. Perera, R. A. Attalage, K. K. C. K. Perera, and V. P. C. Dassanayake, "Designing standalone hybrid energy systems minimizing initial investment, life cycle cost and pollutant emission," Energy, vol. 54, pp. 220230, Jun. 2013.

[65] K. Deb, "An efficient constraint handling method for genetic algorithms," Comput. Methods Appl. Mech. Eng., vol. 186, no. 2-4, pp. 311-338, Jun. 2000.

[66] A. T. D. Perera, R. A. Attalage, K. K. C. K. Perera, and V. P. C. Dassanayake, "Converting existing Internal Combustion Generator (ICG) systems into HESs in standalone applications," Energy Convers. Manag., vol. 74, pp. 237-248, Oct. 2013.

[67] S. Coccolo, J. Kaempf, D. Mauree, and J.-L. Scartezzini, "Cooling potential of greening in the urban environment, a step further towards practice," Sustain. Cities Soc., Jan. 2018. 